\title{
Computational monitoring in real time: review of methods and applications
}

\author{
Arcady V. Dyskin · Hakan Basarir · James Doherty • Mohamed Elchalakani • \\ Grand R. Joldes • Ali Karrech • Barry Lehane · Karol Miller • \\ Elena Pasternak • Igor Shufrin $(\mathbb{D} \cdot$ Adam Wittek
}

Received: 23 December 2017/ Accepted: 15 May 2018/Published online: 19 June 2018

(C) The Author(s) 2018

\begin{abstract}
Continuous monitoring of mechanical parameters determining the state of natural and manmade systems is essential in a wide range of engineering disciplines from mechanical to civil and geotechnical engineering. To be effective, the monitoring response time needs to be commensurate with the characteristic time of variation of the processes being monitored e.g. from seconds as for example in some machinery, to weeks and months for mining excavations and years in the case of structures. The methods of measurement can therefore differ
\end{abstract}

A. V. Dyskin · H. Basarir · J. Doherty .

M. Elchalakani · A. Karrech · B. Lehane

School of Civil, Environmental and Mining Engineering,

The University of Western Australia, 35 Stirling

Highway, Crawley, WA 6009, Australia

I. Shufrin $(\bowtie)$

Department of Structural Engineering, Faculty of Engineering Sciences, Ben-Gurion University of the Negev, P.O. Box 653, 84105 Beer-Sheva, Israel

e-mail: shufrin@bgu.ac.il

G. R. Joldes · K. Miller · A. Wittek

Intelligent Systems for Medicine Laboratory, School of Mechanical and Chemical Engineering, The University of Western Australia, 35 Stirling Highway, Crawley,

WA 6009, Australia

E. Pasternak

School of Mechanical and Chemical Engineering, The University of Western Australia, 35 Stirling Highway, Crawley, WA 6009, Australia significantly for different applications. In spite of this, the methods of information processing-the computational monitoring — have considerable commonality. This review focuses on the methods of computational monitoring in solid and structural mechanics problems in different engineering applications. The traditional methods of monitoring are reviewed along with the corresponding computational and measurement methods. The basic principles of the computational monitoring in real time are established.

Keywords Monitoring - Continuous measurement . Real time

\section{Introduction: general definition and aims}
1.1 Definition of computational monitoring in real time

Acquiring continuous information about performance and integrity of engineering systems in real time is essential for efficient operation of many structural, mechanical and geotechnical systems, such as bridges, offshore and subsurface structures, power generation systems, rotating machinery, buildings, geotechnical foundations, boreholes and mining excavations and tailings and even in the cases involving living matter. Nowadays, the real time monitoring of system 
conditions is a routine for manufacturing, maintenance and the use of many engineering applications. The monitoring process involves the observation of a system, analysis of the obtained data and prediction of the future performance. Modern developments in sensor, communication and signal processing technologies together with computational capabilities enable high accuracy measurement and reliable evaluation of behaviour of engineering systems.

Various monitoring techniques have been developed to control the state of different engineering systems. Some techniques are visual and others employed sensors to monitor the system conditions and detect faults. Commonly these methods require a large number of sensors to provide the complete description of the system. The more complicated the system is, the larger number of sensors is needed. Furthermore the location of these sensors becomes increasingly important (Giniotis and Hope 2014). Adaptive sampling strategies that define the position of the sensors based on physical models are becoming an essential tool for the reliable assessment of engineering systems.

Generally, monitoring procedures are categorised as model-based and signal-based (Huston 2010; Farrar and Worden 2012; Stepinski et al. 2013). Although both approaches rely on signal processing techniques, model-based monitoring methods rely on mathematical or physical models of the system being monitored with the model parameters being estimated in the process of monitoring. The model-based methods play a vital role in the monitoring of structural loads and evaluation of remaining useful life of the system.

Signal-based or data-based monitoring methods, on the other hand, process direct measurements to relate the perceived system parameters to the signal features. A statistical model of training data can be established through machine learning approach for all possible states of the system. At the monitoring stage, the measured data is assigned a corresponding state using pattern recognition algorithms (Huston 2010; Farrar and Worden 2012).

We define computational monitoring as a hybrid approach. The aim of the computational monitoring is to estimate the state of an engineering system from measured data in real time by employing an adaptable computational model, which can be updated and adjusted to the current conditions. The implementation of the computational models into the monitoring process leads to more efficient monitoring and more accurate interpretation of the results. Computational monitoring enables development of self-calibrating monitoring systems and enhances system identification capabilities of monitoring systems.

This review focuses on the integration of real time monitoring and measurement with computational models to achieve predictive power.

\subsection{Motivation for computational monitoring in real time}

A number of engineering systems in exploitation are near the end of their design life. Methods for assessment of the remaining useful life are required to extend the operation of these systems beyond the basis service life. Real time monitoring techniques implementing physical models for reliable damage and fault detection are essential for the safe use of these ageing systems. Computational monitoring offers prospects for development of adaptive methods, which can account for the changing conditions.

Some engineering systems employ novel materials whose performance over time is not yet well established. These systems necessitate continuous monitoring that would measure the performance of the novel materials and improve the service time prediction. Furthermore, transition to more cost-effective systems may require a lowering of safety margins. In this case, the safety demands more accurate monitoring. The information about the system behaviour can be updated using long-term monitoring observations and implemented through computational modelling to optimise operational performance.

Under extreme events, the rapid condition monitoring is required to assess the integrity of the engineering systems and warn of the approaching failure or even catastrophe. In this situation, the computational monitoring enables quick implementation of rapidly changing conditions.

While failure of an engineering structure or a structure in the Earth's crust is usually an instantaneous event that forms a critical point on the time axis, the processes leading to this critical event take time to progress. Naturally the monitoring targets these processes, whose pace determines the notion of 'real time'. Here we assume that these processes are characterised by their characteristic times; the characteristic time of the process is the time required for it 
to exhibit noticeable change. We also assume that the minimum characteristic time of the processes leading to the failure of the system is known and will refer to it as the characteristic time of the system. Subsequently, monitoring in real time refers to the monitoring method whose aggregated reaction time (the time needed for acquiring and processing the information and displaying the results in a form conducive for decision making) is below the characteristic time of the system being monitored.

\subsection{Computation monitoring in real time for intelligent monitoring systems}

Computational monitoring is a next logical step in condition and structural health monitoring procedures. Historically, it started from non-destructive testing and evaluation (NDTE) (Farrar and Worden 2012; Stepinski et al. 2013). The NDTE methods were predominantly used to detect and characterise the damage at a predefined location. Commonly the NDTE techniques were implemented offline after the damage was located (Farrar and Worden 2012). Condition monitoring (CM) methods progressed to allow damage and fault detection in engineering systems during their operation. The $\mathrm{CM}$ has been usually used for monitoring of rotating and reciprocating machinery employed in manufacturing and power generation (Farrar and Worden 2012). Structural health monitoring (SHM) advanced to predict faults at early stages. SHM involves advanced sensor technologies to observe a structure or a mechanical system over time at predefined time increments. These observations are then processed to extract damagesensitive features and statistically analysed to determine the health state of the system (Farrar and Worden 2012). Damage detection in SHM reduces to a problem of statistical pattern recognition implemented through machine learning algorithms (Farrar and Worden 2012). The fundamental challenge of SHM is to capture the system response on widely varying length and time scales required for an accurate establishment of the statistical models (Deraemaeker and Worden 2010).

Recent developments in miniaturisation and embedding technologies for sensors and actuators have been shifting the signal-based paradigm of SHM towards hybrid methods, in which physical and mathematical models of the system are required to design the monitoring system and establish the features for damage identification. The concept of smart materials and structures is another driving force changing the monitoring approaches. A smart engineering structure must not only integrate an ability to detect damage but also be able to self-heal itself. Computational monitoring in real time plays an essential role in development of these smarter engineering systems.

\subsection{Components of computational monitoring in real time}

Computational monitoring is a multidisciplinary research field including a number of basic sciences, such as mechanics, material science, electronics and computer science. The main components of a real time computational monitoring system are

- Non-destructive testing and evaluation

- Signal processing

- Analysis and interpretation of monitoring data

- Sensor and actuators

- High performance computing

A monitoring system can be designed to address the global, local and component levels (Hunt 2006; Giniotis and Hope 2014). The global level monitoring observes the environment in which the engineering system is located. It recognises the influence of the surroundings and other autonomous engineering systems. At the local level, parameters defining health and performance of the system are monitored. This monitoring level is set to detect damage, control operational conditions and forecast future behaviour of the system. The component level monitoring only considers parameters that are important for the functionality of a specific component. In terms of the computational monitoring concept, these levels can be treated in the frame of a multi-scale computational model, which has become very popular in various engineering fields, see for example Crouch et al. (2013), Kim et al. (2013), Bogdanor et al. (2015), Guan et al. (2015) and Jenson and Unnikrishnan (2015).

Any monitoring system would consist of hardware and computational/software parts. The hardware part includes various sensors (Giniotis and Hope 2014), actuators, signal acquisition and processing units (e.g. Verma and Kusiak 2012; Kusiak et al. 2013), 
communication devises and power supply units. Nowadays, these modules become a part of the system architecture. The traditional structural monitoring sensors, such as strain gauges, accelerometers, temperature gauges, etc., are replaced with embedded MEMS and fibre optic sensors (e.g. Maalej et al. 2002; Hunt 2006; Huston 2010; Stepinski et al. 2013; Di Sante 2015). The power supply range, which is significantly broadened by applications of smart materials includes wire based, wireless and energy harvesting methods (Priya and Inman 2008; Annamdas and Radhika 2013). Wireless communication has become a method of choice for the data transfer (Lynch 2006; Uhl et al. 2007).

The software part contains data normalisation, data cleansing, data compression, and feature extraction units. The model-based methods also include packages for the analysis of engineering systems.

We need to add to this list that non-destructive testing and evaluation are based on measurements that could be both direct and indirect; the latter require interpretation models to express the results of the measurements in terms of the monitoring data. Furthermore, the parameter estimation from the measurements may require model calibration and in some cases additional measurements, which necessitates the inclusion of a measurement-computation loop. Finally, the monitoring results in developing (generalised) recommendations, be it verbal/written directives or digital signals to the actuators employed. These considerations can be expressed in terms of a diagram, Fig. 1.

In this paper, we discuss different components of monitoring systems with the aim to expose the state of art in monitoring as it is seen from different fields of engineering. We review the traditional areas of monitoring and give an outlook on methods of interpretations of monitoring data. We review measurement methods for monitoring with a particular emphasis on the methods supporting continuous real time observations. We also discuss computational models that are suitable for computing in real time. The review is concluded with the examples of computational monitoring in geotechnical engineering.

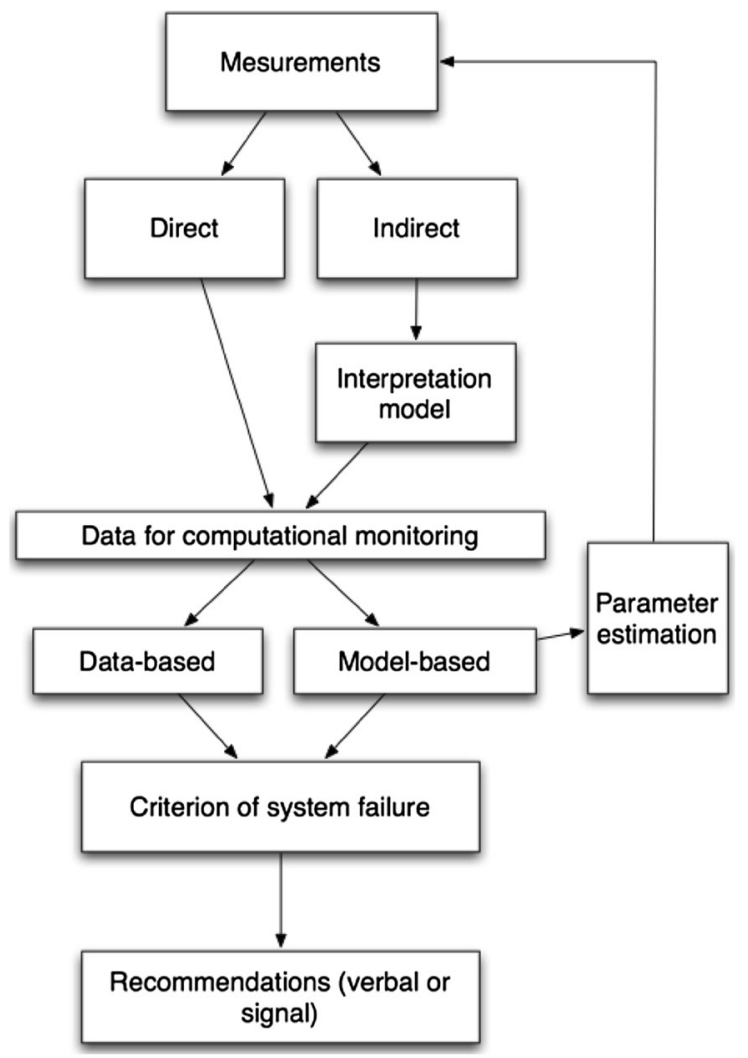

Fig. 1 Schematics of a computational monitoring system

\section{Traditional areas of application of monitoring}

\subsection{Condition monitoring}

Condition monitoring (CM) focuses on early detection of failures and wear of machinery with the intention to minimize downtimes and operational costs. The CM data is commonly used to give a probabilistic forecast of the future conditions or the remaining useful life of the equipment (Marwala 2012). The $\mathrm{CM}$ is an important tool in the condition-based maintenance of machinery, which is widely replacing the more expensive run-to-failure and time-based preventive maintenance approaches (Jardine et al. 2006; Peng et al. 2010; Goyal and Pabla 2015). In the conditionbased maintenance, the maintenance actions are undertaken based on real time observations and prognosis of the remaining useful life of the machine components established through a condition monitoring process (Jardine et al. 2006).

In general, the condition monitoring process includes the following five consecutive steps: (1) data 
acquisition step consisting of direct measurement of engineering parameters such as displacements, accelerations, strains, temperature and etc., (2) data analysis step processing the obtained data, (3) feature selection step determining specific aspects of the data, which can be used as failure indicators, (4) decisions making step identifying system failures through interpretation of the system feature and (5) condition diagnosis step concluding the process by giving estimation to the state of the system (Marwala 2012).

The CM techniques include:

- Vibration based CM that deals with measurement and analysis of machine characteristics in frequency or modal domains. This is the most known CM method, which allows detection of various types of failures. As discussed in recent review papers, the application areas for the vibration based $\mathrm{CM}$ are ranging from structural engineering (Carden and Fanning 2004) and wind turbines (Hameed et al. 2009; Kusiak et al. 2013; De Azevedo et al. 2016) to diagnostics of electrical motors (Nandi et al. 2005) and gearboxes (Lei et al. 2014; Li et al. 2016), monitoring of rolling bearings (El-Thalji and Jantunen 2015) and tool condition monitoring in drilling and cutting operations (Rehorn et al. 2005);

- Acoustic based CM that detects and analyses the elastic waves generated by rapidly released energy from local events, such as cracks, impacts, leaks, and similar events (Li 2002; Kusiak et al. 2013; Yan et al. 2015; De Azevedo et al. 2016);

- Monitoring of electrical effects. This technique is typically performed for monitoring of electrical equipment, such as generators, motors, etc. It uses voltage and current measurements to detect an unusual phenomenon in the equipment such as electric motors (Nandi et al. 2005) and induction machines (Bellini et al. 2008; Zhang et al. 2011);

- Lubricant analysis (oil debris monitoring). This type of CM is mostly performed off line. The oil samples are analysed in the laboratory for presence of wear debris, viscous properties and particles' count and shapes (El-Thalji and Jantunen 2015; Phillips et al. 2015; De Azevedo et al. 2016);

- Thermography. This technique allows for identification of failed components based on their thermal images. It is used for monitoring of faults in electronic parts, deformation monitoring, corrosion and weld monitoring and machinery inspection (Bagavathiappan et al. 2013; Kusiak et al. 2013);

- Ultrasound testing. This technique is used for evaluation of material degradation through relating the properties of the material to ultrasonic wave propagation (Jhang 2009). Among the most common applications are determination of material thickness and the presence of flaws and bearing inspections (Kusiak et al. 2013; El-Thalji and Jantunen 2015).

- Performance monitoring. This method is based on evaluating deviations in the equipment efficiency (Hameed et al. 2009; Kusiak et al. 2013).

A central part of any $\mathrm{CM}$ procedure is the fault detection and isolation (FDI). The FDI methods can be classified into model-based, signal-based, knowledgebased, hybrid (combining two or more other methods) and active control methods.

The model based FDI uses a model of the process being monitored to compare the measured output to the model-predicted one. In these methods, the model of the engineering system is obtained based on the physical principles or using systems identification techniques (Kozin and Natke 1986; Koh et al. 2003). Many model-based FDI methods have been developed during last four decades, e.g. see reviews (Isermann 2005; Heng et al. 2009; Marzat et al. 2012; Gao et al. 2015a, b). The model-based fault detection methods can be categorised as deterministic FDI, stochastic FDI, fault diagnosis for discrete-events and hybrid systems, and fault diagnosis for networked and distributed systems (Gao et al. 2015b). Deterministic model-based FDI methods include variety of the observer based methods and parity equations or parity space methods (Isermann 2005; Gao et al. 2015b). The stochastic model-based methods commonly use Kalman filter and the parameter estimation techniques. The Kalman filter method statistically tests residuals generated by Kalman filters in a structure similar to the observed one. The parameter estimation techniques identify and compare the reference parameters obtained from real time measurements and under healthy conditions (Gao et al. 2015b). Discrete-event fault diagnostics is represented by automata-based and Petri-net-based fault detection methods (Gao et al. 2015b). Another hybrid fault diagnostics systemsthe bond graph method-recently become a popular 
approach to FDI in complex engineering systems. This method combines a discrete-event model based on observable events of the discrete dynamics with modechange detection and isolation techniques of the continuous dynamics (Levy et al. 2014). Network fault diagnostics refers to the monitoring via wireless and networking communication channels. The recent network technologies have brought new challenges into the monitoring field, such as overcoming transmission delays, data dropouts, and limited capacity of the communication channels. The model-based FDI methods addressing these challenges were reviewed in Gao et al. (2015b). The distributed fault diagnosis treats a complex industrial process as an assembly of subsystems, where each subsystem is monitored separately (Marwala 2012). The main advantages of this distributed system are the reduced use of network resources and its readiness for extension. Recent development in this area were also discussed in Gao et al. (2015b). The distinctive advantage of all modelbased FDI methods is that they are able to diagnose unknown faults using a small amount of data. At the same time, this diagnostic heavily relies on accuracy of the employed model.

If no adequate model is available, the condition monitoring is performed using signal-based methods utilising the measured process history and real time signal. The fault detection is based on the symptom analysis and prior knowledge of the healthy system. The signal-based FDI can be categorised as timedomain, frequency-domain and time-frequency signal-based methods (Gao et al. 2015b). The timedomain signal-based methods perform fault detection by extracting the time-domain features such as mechanical vibrations, changes of electric and induction current characteristics over time and impulse excitations are among the methods cited in Gao et al. (2015b). The frequency-domain signal-based methods make use of spectrum analysis to detect changes and/ or faults. Frequency analysis of vibration signal is a common approach to $\mathrm{CM}$ of rotating machinery (Marwala 2012; Gao et al. 2015b). The time-frequency signal-based methods are mainly used for monitoring of systems featured by nonstationary signals. Among the methods that fall under this category are the short-time Fourier transform (Nandi et al. 2005; Cabal-Yepez et al. 2013), wavelet transforms (Cabal-Yepez et al. 2013), Hilbert-Huang transform, and Wigner-Ville distribution (Gao et al. 2015b). The main feature of the signal-based methods is that there is no need in a predefined model of the system. This is especially important for complex engineering systems where an adequate explicit system model is not available. On the other hand, the signal-based methods do not account for unbalanced input conditions, such as load deviations or power supply disturbances. Another deficiency of the signalbased methods is the need for historical data under both normal and faulty conditions.

In contrast to the model- and signal-based methods, which require either a predefined model or a signal pattern, the knowledge-based models are build on historical data only and so they are often referred as data-driven FDI method (Gao et al. 2015a). The knowledge-based systems are classified as qualitative and quantitative. The qualitative methods are represented by the expert-system-based method, qualitative trend analysis and signed directed graphs (Gao et al. 2015a). The quantitative methods are categorised as statistical- and non-statistical knowledge-based fault diagnosis. The statistical methods require a large amount of training data to adequately model the process (Gao et al. 2015a). The quantitative statistical methods include principal component analysis, partial least squares, independent component analysis, statistical pattern classifiers, and support vector machine (Samanta 2004; Widodo and Yang 2007; Phillips et al. 2015). The quantitative non-statistical methods are represented by artificial neural network and fuzzy logic approaches (e.g. Li 2002; Samanta 2004; Nandi et al. 2005; Basarir et al. 2007; Heng et al. 2009; Gao et al. 2015a). The training approaches for all knowledge-based methods are categorised as supervised and unsupervised modes. In the unsupervised mode, a knowledge base is formed by the data obtained from the normal operations. The real time measurements are then evaluated against this knowledge base. In the supervised mode, the data is trained using both normal and faulty conditions. The main weakness of the knowledge-based methods is the large computational costs associated with the large amount of historical data. The classification methods for new faults in complex systems may become a challenging task as well.

The hybrid FDI methods are introduced to overcome the limitations of the basic methods. Signal- and knowledge-based methods are naturally combined by using data driven classifiers on a basis of features 
extracted by a signal-based approach (as discussed in Gao et al. 2015a). The knowledge-based methods have been used to update statistical models in model-based FDI (Gao et al. 2015a; Laouti et al. 2015).

The active control FDI refers to a series of methods that enhances the fault detection capability by introducing specially designed input signal. This signal allows for more reliable identification of faulty modes (Gao et al. 2015a).

A large number of studies dealing with various aspects of the condition monitoring have been published and diverse FDI algorithms have been developed. Different methods have different limitations, which sometimes can be overcome by combining several methods together into hybrid methods. However, there are a number of common challenges remaining in CM (Heng et al. 2009). Among the areas that needed improvement are the integration between $\mathrm{CM}$ techniques, incomplete training/measurement data, influence of maintenance actions, varying operational conditions, coupled failure modes and full automation (Heng et al. 2009).

\subsection{Damage detection and modelling}

Damage is one of the major causes of failure in materials and structures. In recent years, damage mechanics has attracted an increasing interest in civil, aeronautical and mechanical engineering communities to prevent sudden failure by detecting damage in the early stages of service and/or predicting its initiation/propagation due to external loading. Various non-destructive techniques that rely on the overall changes of physical properties have been introduced to detect the presence of damage, assess its severity and identify its location within complex mechanical structures.

\subsubsection{Non-destructive damage detection}

Comprehensive surveys on damage detection and monitoring of engineering systems through changes in their vibration characteristics were given in Doebling et al. (1996), Salawu (1997), Doebling et al. (1998), Fan and Qiao (2011), Thatoi et al. (2012) and Stepinski et al. (2013). This type of monitoring can be used to diagnose damage in cracked beams, shells plates, pipelines (Wauer 1990; Dimarogonas 1996; Sabnavis et al. 2004) as well as composite materials
(Montalvo et al. 2006). The methods of crack detection can also use the crack-induced bilinearity whereby the elastic modulus in tension is affected by the crack opening and hence smaller than that in compression, since the modulus is little affected by the crack that gets closed under compression (e.g. Adler 1970; Prime and Shevitz 1996; Rivola and White 1998; Chondros et al. 2001; Peng et al. 2008; Lyakhovsky et al. 2009), see also review and the discussion of properties of bilinear oscillators in Dyskin et al. (2012, 2013, 2014).

Among the novel methods of damage detection, it is also worth mentioning the impedance-based techniques. When bounded to mechanical structures Piezoelectric patches can be used as sensors/actuator to monitor and detect damaged elements (Naidu et al. 2002; Park et al. 2003). The detection approach consists in comparing the early age frequency response functions to the posterior responses. The eventual modifications of the signals can be attributed to the presence of damage (Raju 1997). For example, statistical process control (SPC) is a signal based method that monitors the changes in a process and relates them to specific operational conditions, in particular possible damages to the system (Farrar and Worden 2012). Damage prognosis (DP) is used to assess the remaining useful life of a system after damage is located (Farrar and Worden 2012). In geotechnical applications investigation of wave propagation is widely used to detect the internal damage, in particular the types of cracks can be inferred from the wave velocity variations with external load (Khandelwal and Ranjith 2010; Zaitsev et al. 2017a, b).

As a third category of non-destructive testing, infrared thermography offers a damage detecting method that does not rely on mechanical properties (Cielo et al. 1987; Muralidhar and Arya 1993; Lüthi et al. 1995). This technique monitors the effect of local defects on the heat flow trajectories. In a highly conductive medium the lines of heat transfer are predictable and well defined. They can be distorted locally in the presence of intrusive bodies or upon development of damage zones. Infrared cameras can be used to illustrate such anomalies (Sham et al. 2008).

Electromagnetic fields can also be useful to detect damage in civil infrastructures through Ground Penetrating Radar (GPR) (Xiongyao et al. 2007; Parkinson and Ékes 2008; Yelf et al. 2008). GPR uses an antenna containing a transmitter and a receiver that 
send electromagnetic waves through the subsurface of the monitored infrastructure. As the antenna is moved along predefined paths, energy is recorded in real time on radargrams that indicate the presence of anomalies associated with the change of dielectric properties.

\subsubsection{Damage modelling}

Modelling of the damage is usually based on Continuum damage mechanics theory, which was established in the pioneering works of Kachanov (1958) and Rabotnov (1969) that defined the concept of "effective" stress in materials embedding defects. Lemaitre and Chaboche introduced thermodynamic formulation and constitutive models that can predict the degradation of metallic materials due to mechanical loading (Lemaitre 1985; Chaboche 1987; Lemaitre and Chaboche 2001). Karrech et al. introduced a temperature dependent damage model to describe the damage of the lithosphere (Karrech et al. 2011a), a pressure and temperature dependent damage mechanics model for subsurface crustal strata (Karrech et al. 2011b), fluid flow dependent damage (Karrech et al. 2014), and fractal damage of materials with self-similar distribution of defects (Karrech et al. 2017). In the cases when the type of defects is known, the formulation of the constitutive model can be assisted by the theory of effective characteristics, e.g. Salganik (1973), Vavakin and Salganik (1975, 1978), Dyskin (2002, 2004, 2005, 2006, 2007, 2008) developed mechanics of materials (including geomaterials) with self-similar distributions of cracks or fractures.

\subsection{Monitoring of mining operations}

Instrumentation and monitoring are used in mining sector to make sure that the constructed mining engineering structures such as slopes, large underground openings, tailing dams behave according to the expectations defined at the design stage.

In open pit mines different forms of monitoring systems have been used to predict slope stability (Sakurai 1997). Previously monitoring points were fixed in the field and monitored periodically, whereas with the recent technology more improved systems such as slope monitoring radar have been used.

For underground mines the application area of monitoring is much wider than for the open pit mining. Continuous and periodic measurements are conducted for both early warning and calibration of numerical models. In addition to this in underground coal mining continuous monitoring is mandatory for the detection and observation of poisonous and combustible gasses i.e. $\mathrm{CO}$ and methane.

Field measurement studies are very important for both evaluation of the performance of existing and designed support elements and for calibration of numerical models. Numerical model calibration is a way of reliably estimation of strength properties of rock mass and reduction of uncertainties (Sakurai 1997). The calibration studies include the comparison of modelling results with the field measurements. During the calibration process, the input parameters are modified in a systematic manner until satisfactory agreement between the model results and field measurements is achieved. When the model is calibrated then it can be applied to evaluate similar mining layout and geological conditions.

\subsection{Hydraulic fracture monitoring}

Hydraulic fracturing is a technique used in the petroleum industry for reservoir stimulation, especially in tight gas reservoirs, in geothermal technologies, as well as in mining industry for block caving stimulation and for stress measurements. It involves cracking of the rock formation using high pressure fluids applied to a borehole. The success of hydraulic fracture operations vitally depends upon the direction and the dimensions of the produced fracture. Given that the hydraulic fracturing is very sensitive to the directions of the principal in situ stresses, to the distribution of pre-existing fractures and to the rock strength it is important to monitor the direction and dimensions of the hydraulic fracture.

A number of methods is used or proposed for hydraulic fracture monitoring. They include fracturing fluid pressure analysis, tracing the fracture fluid, microseismic mapping, crosswell seismic detection, vertical seismic profiling, measuring the surface tilt.

Conventional tracing the hydraulic fracture employs adding chemical and gamma-emitting tracers into the fracturing fluids (King 2011). Microseismic monitoring based on locating the signal sources, socalled passive microseismic mapping became quite popular. The passive microseismic mapping provides images of the fracture by detecting microseisms or micro-earthquakes that are triggered by shear slippage 
on reactivated bedding planes or natural fractures adjacent to the hydraulic fracture (Cipolla and Wright 2000).

An interesting development is the acoustic method based on generating the seismic waves from within the fluid itself by injecting the so-called noisy proppant (Willberg et al. 2006). The noisy proppant consists of small granular explosives which are floated into the fracture and under certain pressure explode to announce their position to surface mounted receivers. A modification of this method was proposed by Dyskin et al. (2011) whereby the explosive is replaced by more safe electronic pulse-emitting particles (which we term screamers) capable of synchronising themselves to create interference which increases the long wave energy content of their combined output. Both methods are active acoustic (microseismic) methods based on installing artificial noise-emitting devices.

Another method consists of the surface tilt monitoring and is based on the measurement of the fractureinduced tilt at many points above a hydraulic fracture (see lit. review in Mahrer 1999). In essence, it is a variant of strain measuring technique, as the surface tilt is a component of shear strain on the surface. The determination of fracture parameters requires solving a geophysical inverse problem, which possess a certain computational challenge.

\subsection{Measurement while drilling}

Measurement While Drilling (MWD) refers to the measurements taken downhole with an electromechanical device located in the bottom hole assembly of the drill string in the borehole drilling. The data obtained during drilling of exploration or production holes can reduce the cost and time and increase the accuracy of the site evaluation. The interpretation of the drill performance parameters, such as penetration rate, thrust on the bit, rotary speed and torque enables extracting the information regarding the rock mass properties.

Drill monitoring studies are not new in mining and can be traced back to the seventies (Brown and Barr 1978), Deveaux et al. (1983) and Schneider (1983) for detecting weak and water bearing zones. Multichannel data logging by Brown and Barr (1978) demonstrated that monitored drill parameters could be used to locate fractures and discriminate between lithologies. With the technological advancements, recently more research in mining sector have been focused on MWD technique. Detailed information regarding rock type, lithology, rock strength (Hatherly et al. 2015; Basarir and Karpuz 2016), ground characteristics (Kahraman et al. 2015) can all be potentially determined from the recorded drilling parameters. This data recorded with respect to depth in the borehole must however be interpreted by direct comparison, correlation and calibration with core logs. It needs to me noted that, the MDW technique has a predecessor, the so-called under-excavation technique (Wiles and Kaiser 1994a, b) implying the in situ stress determination by measurements as an opening is excavated.

\section{Methods of measurements for monitoring}

The measurement is an essential part of any monitoring system. The measurements methods for monitoring should be non-destructive, robust to changes in the operational conditions and able to function over long periods of time. A number of methods that satisfy these requirements have been developed and used in the traditional areas of monitoring and experimental research studies. This section reviews different measurement methods suitable for the computational monitoring in real time.

\subsection{Strain gauge monitoring}

Strain gauges are the common tool for the measurement of deformations of solids and structures. They are inexpensive, simple in use and having various sensitivity levels. The strain gauges can be used for monitoring the external and internal deformations. For example, the electric resistance strain gauges are often used to monitor the strain inside the steel reinforcing bars (e.g. Maalej et al. 2002; Hunt 2006; Huston 2010; Stepinski et al. 2013; Di Sante 2015). For example, for $120 \mathrm{Ohm}$ resistance strain gauges, the strains can be calculated as Strain (micro-stain) $=C I \times$ Volt $/$ $(2.5 G \times F)$, where $\mathrm{F}$ is the gauge factor, $\mathrm{G}$ is the gain, $\mathrm{CI}$ is connection index that is 1,2 , or 4 for full bridge installation, 2 for half a bridge, and 4 for one quarter of a bridge, respectively. This approach was used for testing of reinforced concrete members at the Structural Laboratory of the University of Western 
Australia. The example of the sensor application is demonstrated in Fig. 2: a $10 \mathrm{~mm}$ long electric resistance strain gauge of $120 \mathrm{Ohm}$ resistance attached to the surface of reinforcing bar. The tests were conducted on RC columns and beams under static loading conditions. The behaviour of the structural members was monitored by correlating the global displacements measured externally and the rebar strains obtained by the embedded strain gauges. Figure 3 shows the tested $\mathrm{RC}$ column before and after testing. The column is $1200 \mathrm{~mm}$ long and has a square cross section of $180 \mathrm{~mm}$. Figure 4a shows a typical vertical load-axial deflection curve and Fig. 4b shows the vertical loadstrain curve at mid-span of the reinforced concrete column. It is seen that failure load was $1400 \mathrm{kN}$, which occurred at about $5.5 \mathrm{~mm}$ vertical deflection corresponding to 4500 micro-strain. Figure 5 demonstrates the four point bending test for the $\mathrm{RC}$ beam. The beam is $1200 \mathrm{~mm}$ long and has a square cross section of $180 \mathrm{~mm}$ wide. Figure 6a shows a typical vertical loadmid span deflection and Fig. 6b shows the vertical load-strain at mid-span of the reinforced concrete beam. It is seen that failure load was $83 \mathrm{kN}$ which occurred about $8.5 \mathrm{~mm}$ vertical deflection which corresponds to 8500 micro-strain in tension and 500 micro-strain in compression.

\subsection{Close-range photogrammetry}

Strain gauging is complicated and time consuming, and the data obtained are constrained to the typically small strain gauge dimensions, which can be a considerable limitation especially in the case of high heterogeneity of the surface. Typically, the strain gauge is bonded to the surface and careful application of the strain gauge is critical to ensure good measurements. It is estimated that each strain gauge requires

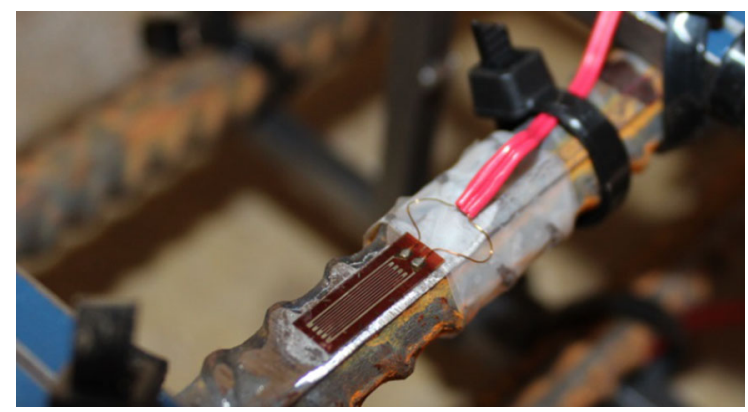

Fig. 2 Strain gauge attached to a reinforcing bar

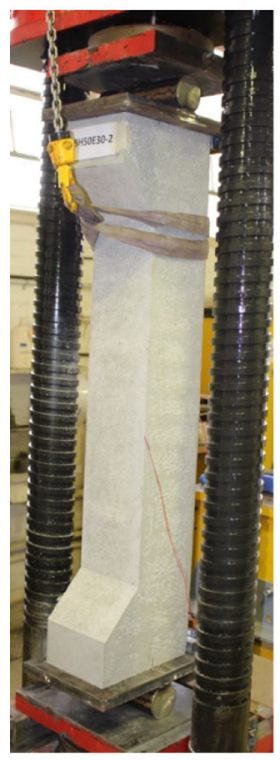

(a)

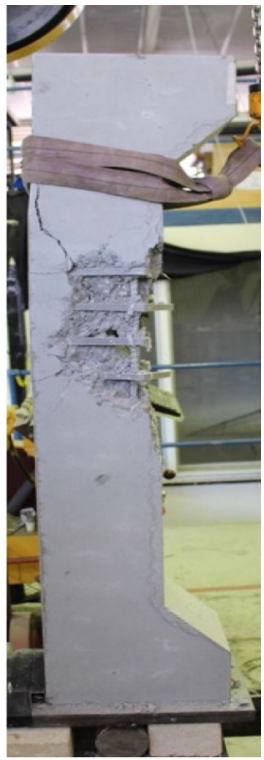

(b)
Fig. 3 Reinforced concrete column before and after loading

2-3 h to apply and prepare for testing. The test engineer selects the positions of each measuring point carefully, using a computer finite-element analysis (FEA) model, and limits the number of strain gauges per component to minimize cost and setup time.

The strain gauge outputs a measurement of the strain at its location and solely in the direction in which it is mounted. Critical areas often have high strain gradients, but strain levels quickly decrease a few millimetres from the hot spot to levels too low to measure accurately. Consequently, the strain gauges are mostly ineffective for strain concentration measurements unless the precise location of the strain concentration is known. This is notoriously difficult with non-homogeneous materials such as rocks, see example in Fig. 7. Furthermore, the development and growth of fractures induced by the stress concentrators could damage the gauges.

It is therefore attractive to use the contactless measuring techniques. Of those, the most popular is the photogrammetry - a method of measuring the geometry of a surface by tracing the changes on the consecutive photographs-originated in geology and geodesy. It is attractive to apply the method for monitoring by measuring the displacement, strain and possibly rotation fields and their evolution. In order to reconstruct the full 3D displacements on the surface a 
Fig. 4 Load versus deflections curve (a) and load versus compressive GFRP strain curve (b) at the mid-span of the reinforced concrete column

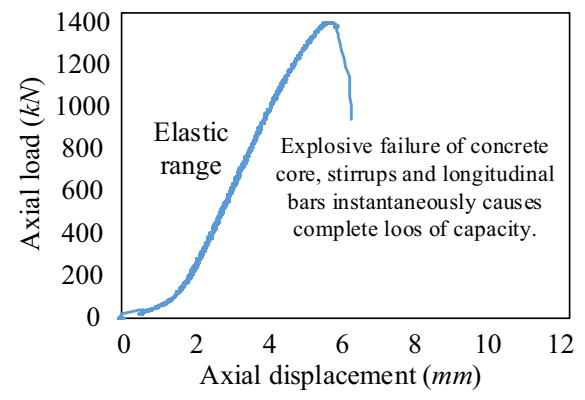

(a)

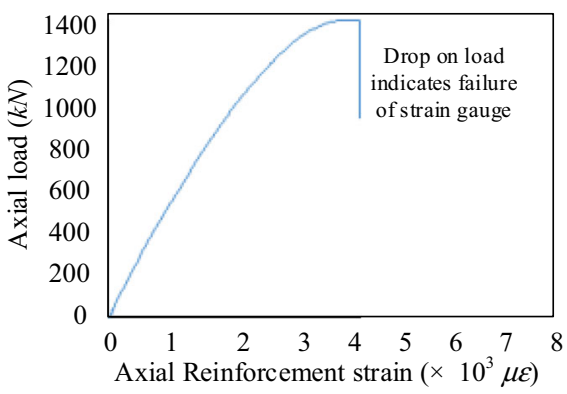

(b)

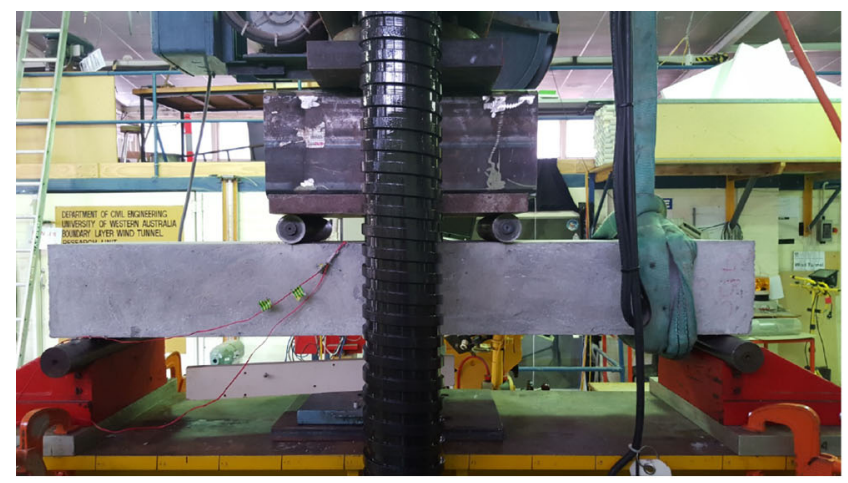

(a)

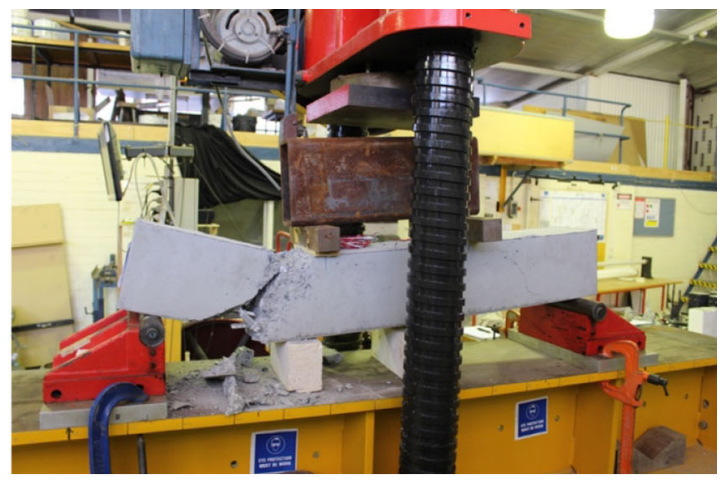

(b)

Fig. 5 Reinforced concrete beam before (a) and after (b) loading

Fig. 6 Reinforced concrete beam load-lateral deflection curve (a) and load-GFRP strain curves (b)

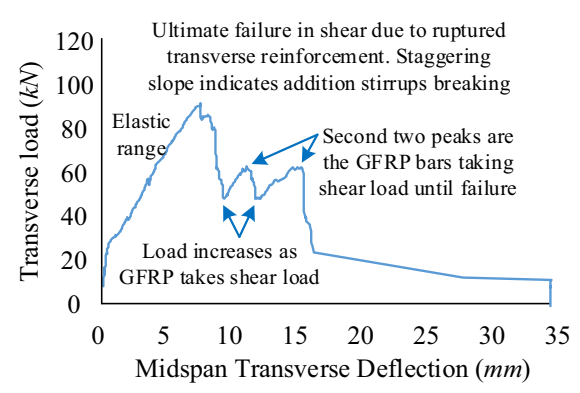

(a)

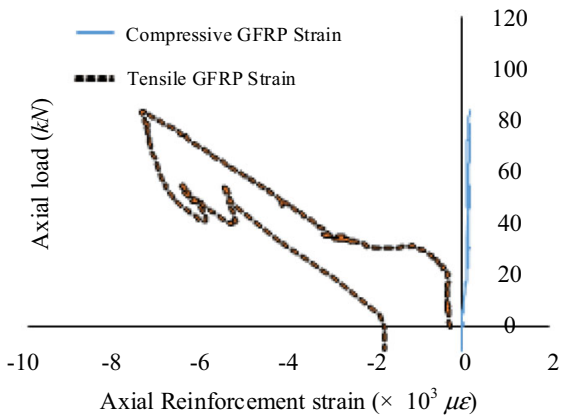

(b) stereo photography is needed, however if only inplane displacements are sought, a single camera can be sufficient.

Currently two methods, the close-range photogrammetry and the Digital Image Correlation (DIC) are the most common. The close-range photogrammetry generates 3D coordinates of specific predefined points of interest at time intervals, whereas the photogrammetric measurement is based on determination of changes in these coordinates. The points of interest are marked beforehand using special artificial markers and coded targets, which facilitate their automatic detection and identification, see examples in Figs. 7 and 8. DIC, on the other hand, is based on pattern matching. Natural or artificially applied pattern of the surface of the test object is divided into correlation areas called macro-image facets or subsets of pixels. These subsets are correlated in each consecutive image to generate strain fields. 
Fig. 7 Photogrammetric measurements in geotechnics

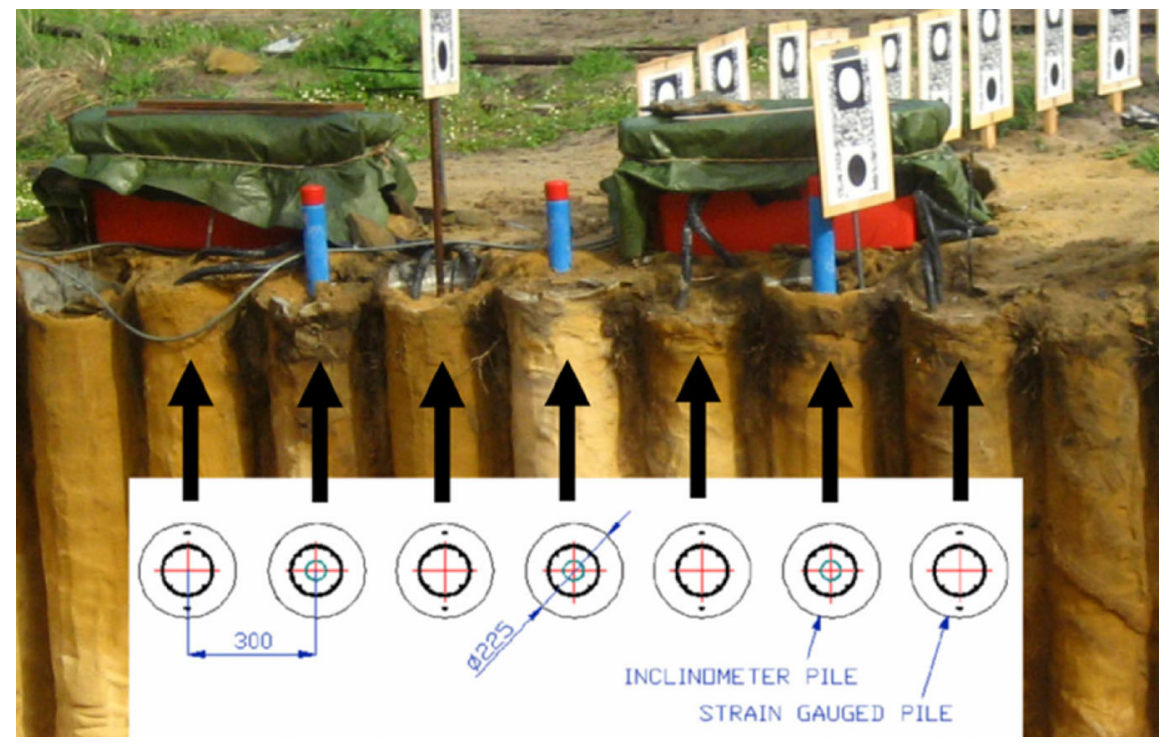

Fig. 8 Close-range photogrammetry measurements of a laboratory prototype: a mark up of points of interest and reference points, b calibration bundle (Shufrin et al. 2016)

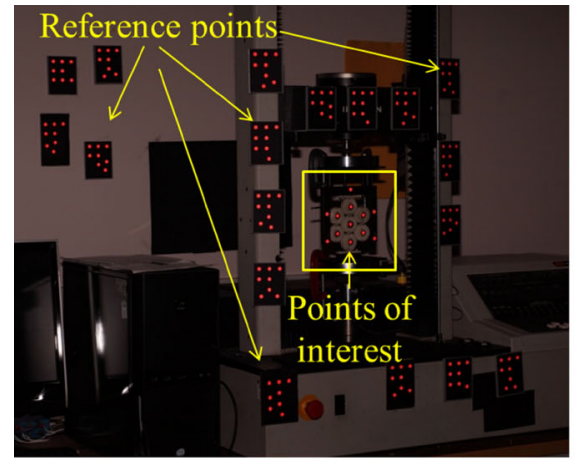

(a)

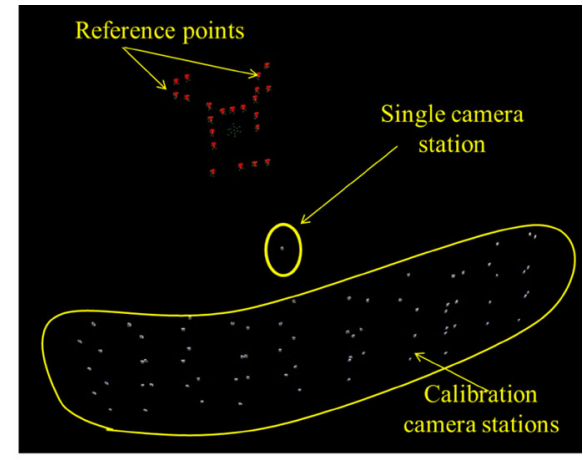

(b)
The close-range photogrammetry is characterised by the ratio of the camera focal length to a distance to the object chosen between 1:20 and 1:1000 and requires special reflective targets that should be fixed to the surface. With this method it is possible to achieve measurement precision of 1:500,000 with respect to the largest object dimension in off-line photogrammetry systems (Fraser 1992; Fraser et al. 2005; Luhmann 2010) and around 1:10,000 in on-line systems (Luhmann 2010). In addition to the high accuracy, the close-range photogrammetry offers a possibility of non-contact measurements, a possibility to monitor a wide network of points without any additional cost and applicability in a wide range of engineering situations. Multi- and single-camera close-range photogrammetry systems were applied to measurement of static (Franke et al. 2006; Jiang et al.
2008; Lee and Al-Mahaidi 2008; Ye et al. 2011) and dynamic deflections (Qi et al. 2014) of various civil engineering structures, capturing vibration (Ryall and Fraser 2002) and buckling (Bambach 2009) modes, assessment of thermal deformations (Fraser and Riedel 2000) and automatic fracture monitoring (Valença et al. 2012). It is also used in laboratory experiments for displacement and strain measurements (Shufrin et al. 2016).

The close-range photogrammetry reconstructs the object simultaneously from several images of the targets taken from different viewpoints by creating bundles of intersecting rays and triangulation. The accuracy of photogrammetric measurements is a function of (1) the number of images (the more images used the higher the accuracy of the bundle adjustment), (2) the spatial geometry of intersecting rays 
(the wider the geometry the smaller the triangulation errors), (3) the imaging scale (the greater the magnification the higher the accuracy of image measurements), and (4) the camera geometric reliability and resolution (Fraser et al. 2005; Luhmann 2006). (The use of so-called metric cameras with stable internal architecture and high resolutions leads to a higher precision.) To obtain high accuracy measurements of a stationary object, one needs to increase the number of camera views significantly by either using multiple cameras or moving the same camera around and taking many images. The latter approach, however, cannot be used to track the continuous deformation process, since an instant deformation state has to be simultaneously captured from numerous camera positions. However, the use of multiple metric or semi-metric cameras attracts high cost and synchronisation problems. The commercial software packages such as iWitnessPRO (Fraser and Cronk 2009) can be used for both camera calibration and measurements.

For example, the procedure allowing for measurement of planar deformations from digital images using a single camera was proposed in Shufrin et al. (2016). Figure $8 \mathrm{a}$ presents the laboratory setup used to measure deformation in the uniaxilly loaded prototype. The displacements are measured at the points of interest marked using special retroreflective targets. The reference points are also distributed around the prototype to provide wide spatial geometry for camera calibration and determination of the stationary position of the camera. Images of the object were taken from the stationary camera position during loading sequences as shown in Fig. 8b. This position is determined with respect to the prototype at the end of the experiment using images taken from calibration camera stations, see Fig. $8 \mathrm{~b}$.

\subsection{Digital image correlation}

Another method that uses the photographic images of the deformed objects is Digital Image Correlation (DIC). It is based on comparison of two images, before and after deformation. The surface should be covered with speckles (e.g. blobs of paint) irregularly placed, see Fig. 9. The algorithm selects subsets of pixels in the image before deformation (the reference image, Fig. 9a). Each subset is then correlated with the subsets from the deformed image and the new position of the subset centre in the deformed image is calculated, Fig. 9a, b. This process is repeated for all the subsets in the reference image and thus the displacement field is reconstructed. The strain field is then determined by differentiation as the symmetrical part of displacement gradient. Different applications were found and various processing methods were developed aimed at increasing resolution (e.g. Peters et al. 1983; Bruck et al. 1989; Chen et al. 1993; Vendroux and Knauss 1998; Pitter et al. 2001; Schreier and Sutton 2002; Wang and Kang 2002; Ma and Guanchang 2003; Pilch et al. 2004; Zhang et al. 2006; Pan and Li 2011; Rechenmacher et al. 2011; Hassan et al. 2017). Currently the error in displacement measurements can be as small as 0.01 pixel size. The strain field is usually determined by differentiation, however algorithms were developed for direct reconstruction of strains (e.g. Lu and Cary 2000).

The method also allows reconstructing the rotations, which is important in modelling and understanding the mechanical behaviour of particulate, granular and fragmented materials and associated processes of fracturing in these materials (Pasternak et al. 2015; Esin et al. 2017; Hassan et al. 2017).

The main advantage of the method is the simplicity of the setup and measurements. However, DIC performance deteriorates in dusty or smoky environment due to unwanted noise (Ha et al. 2009; DebellaGilo and Kääb 2011). Another limitation is that the original DIC is based on the assumption of continuity of the displacement field and therefore is not suitable for measuring displacements in the presence of discontinuities or fractures. Special automatic methods were developed to enable displacement reconstruction in the presence of discontinuities (e.g. Helm 2008; Chen et al. 2010; Poissant and Barthelat 2010; Nguyen et al. 2011; Rupil et al. 2011; Fagerholt et al. 2013; Hassan et al. 2015; MacNish et al. 2015; Hassan et al. 2017). Roux and Hild (2006) and Roux et al. (2009) proposed a post processing technique to reconstruct the strain field around cracks assuming that the crack opening (displacement discontinuity) is always small (in the subpixel range). It should be noted that when the displacements are small the loss of accuracy should be expected.

\subsection{Smart sensor technology}

A smart system is the system, which is able to detect changes in its environment and to response in a certain 
Fig. 9 DIC Speckled pattern and pixel subsets. a Continuous deformation: blue pixel subset is of the reference state and yellow subset is of a deformed image, $\mathbf{b}$ deformed image with discontinuities (Hassan et al. 2017)

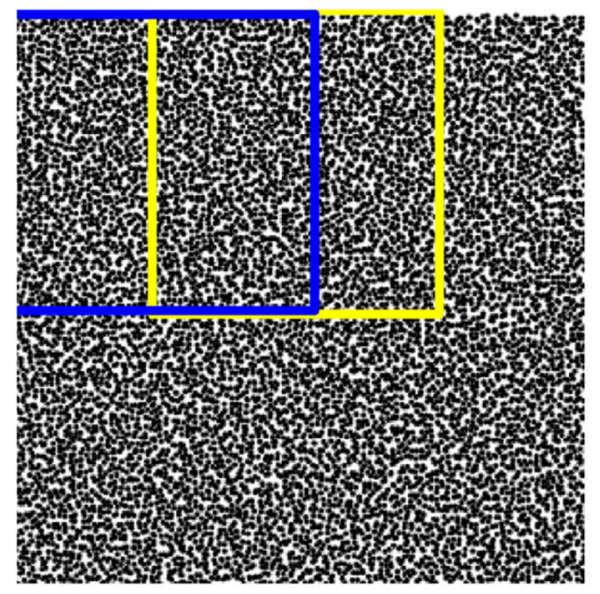

(a)

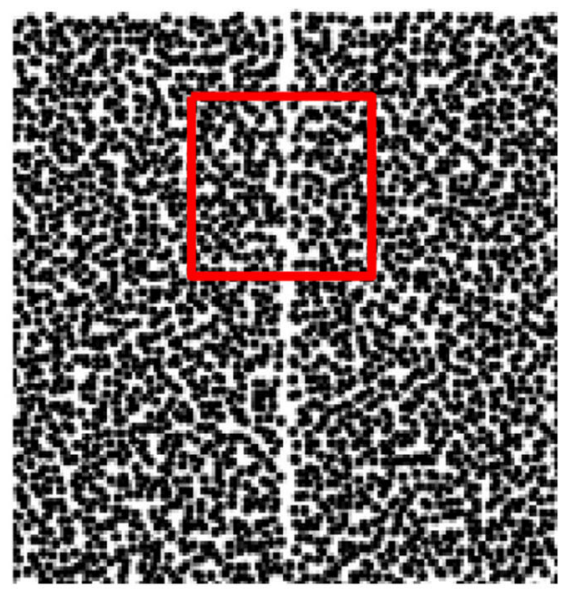

(b) way by altering its mechanical properties, shape or electromagnetic performance (Varadan and Varadan 2000). During the past two decades, these smart abilities have been widely adopted for the measurement and monitoring purposes. The smart sensors are permanently embedded into the structure in a predefined configuration. These sensors are able to provide enhanced monitoring information, which is not obtainable by the traditional sensors. The smart systems include piezoelectric sensors, wireless smart sensors and optical fibre sensors. The comprehensive reviews for the smart sensor technologies can be found in Worden and Dulieu-Barton (2004), Di Sante (2015).

Piezoelectric sensors are made of piezoelectric materials, which exhibit electromechanical coupling between the electric field and the mechanical strain. The piezoelectric sensors are used in impedance-based damage detection application (Park et al. 2003; Kim and Roh 2008; Baptista and Filho 2009; Annamdas and Radhika 2013) and guided waves-based damage detection methods (Park et al. 2006; Sohn and Kim 2010).

The wireless smart sensors networks are widely replacing the traditional wired systems (Zhao and Guibas 2004; Sazonov et al. 2009; Farrar and Worden 2012). Most wireless sensors implement multiple types of measurements, such as impedance-based monitoring, vibration based crack detection, etc. (Jessica 2005; Chintalapudi et al. 2006).

Optical fibre sensors are widely used in monitoring of civil infrastructure. They used to measure strain, temperature and internal pressure. These sensors are light, highly sensitive and insusceptible to electromagnetic interference. The most prominent example of this technology is the fibre Bragg grating, see for example Fig. 10 (Chi-Young and Chang-Sun 2002; Di Sante 2015).

\subsection{Acoustic emission monitoring}

The acoustic emission (AE) monitoring is based on capturing the elastic waves, which are emitted by a developing defect. AE is defined as the rapid release of strain energy from localised sources, such as fracture creation or propagation, plastic deformation or other mechanical performance like friction. The most prominent feature of the $\mathrm{AE}$ testing is that it is a continuous process where the structure is observed under existing loading conditions or even during the loading (Grosse and Ohtsu 2008). Thus, AE allows the real time monitoring capturing the events while they develop. The AE monitoring is used in many areas of engineering and vast comprehensive reviews on its application can be found in literature, e.g. aerospace engineering applications (Holford et al. 2017), testing of polymer composites (Romhány et al. 2017), monitoring of concrete structures (Zaki et al. 2015; Noorsuhada 2016) and hydraulic fracture propagation in rocks (Bunger et al. 2015). 
Fig. 10 Fibre Bragg grating sensor principles (Di Sante 2015)

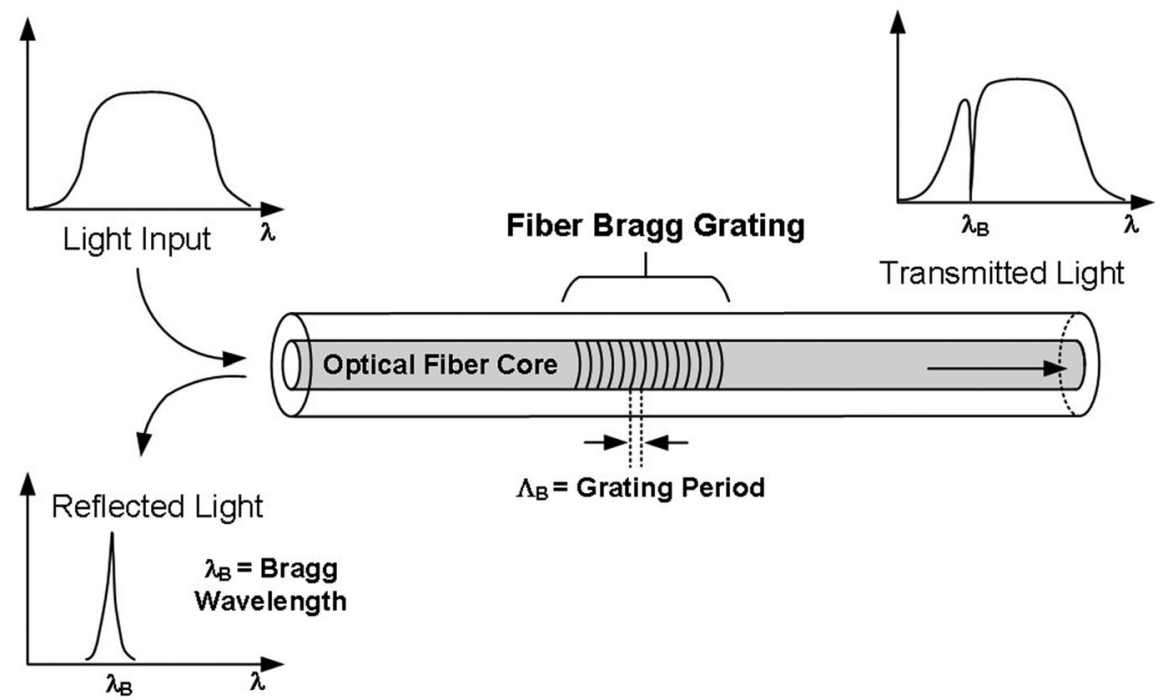

3.6 Infrared thermographic non-destructive monitoring

Infrared thermographic non-destructive testing is a non-contact monitoring method, which is based on mapping surface temperatures of an object by capturing the emitted infrared radiation (IR) (Stepinski et al. 2013). The amount of IR radiation emitted by an object is measured by infrared cameras and recorded as thermal images of the object. The damage is detected through examination of anomalies in the thermal images of the object. The thermographic methods are divided into passive and active methods. The passive thermographic methods are able to detect global anomalies and are qualitative in nature. It is used for leakage detection (Inagaki and Okamoto 1997; Lewis et al. 2003), monitoring of heat losses and structural inspections (Grinzato et al. 2002; Stepinski et al. 2013; Theodorakeas et al. 2015). In the active thermographic monitoring, the energy is supplied to the object by an external source, either by a thermal wave source or by vibration source. The latter approach is called vibrothermography (Stepinski et al. 2013). In vibrothermography monitoring, the mechanical energy produced by the stress waves from the external or embedded vibration source converts into thermal energy at discontinuities, such as cracks, delaminations, etc. Thus, the defect turns into the heat source and can be directly detected on the thermal image. The active thermographic monitoring methods are used for the detection of cracks in ceramic (Kurita et al. 2009), metallic (Kordatos et al. 2012) and composite materials (Fernandes et al. 2015; Mendioroz et al. 2017), delamination failure in composite materials (Fernandes et al. 2015), welding inspection (Schlichting et al. 2012).

\subsection{Electromagnetic emission monitoring}

This method is based on registering electromagnetic emission from moving fracture tips. The emission has been detected at crack propagation in almost all materials (see review by Gade et al. 2014). The detection methods utilise electric or magnetic dipole sensors and capacitors (Gade et al. 2014). Electromagnetic emission is also observed during other fracture processes, for instance in rock samples under uniaxial compression of high magnitude (Mori et al. 2009).

\subsection{Gravitational monitoring}

When rock mass deformation produces volumetric strain the latter leads to change in rock density and the corresponding change in gravity. Even if the change is extremely small, the sensitivity of gravity meters is sufficient to detect it. On top of this, the place where deformation is developed moves, which can also be detected (Walsh 1975). Furthermore, the failure processes and damage accumulation in rocks and rock mass can produce dilatancy that is non-linear increase in volume. This phenomenon can also be measured by 
gravity meters and subsequently lead to the use of gravitational monitoring for fracture and failure monitoring (Fajklewicz 1996). In particular a resemblance of microgravity variations and the microseismic activity in the excavation was obtained. However, there was no correlation observed between microgravity and the advance of the excavation (Fajklewicz 1996). One notes though that the change in microgravity caused by elastic volumetric strain associated with the excavation advance is negative (compression) while the dilatancy related to fracture processes in the rock cause positive volumetric strain such that these two processes could mask each other.

\section{Methods of analysis of monitoring data and system identification}

Analysis and interpretation of monitoring data are usually based on two main approaches: model-based and signal-based methods. The model-based methods involve constructing of a physical model of the system and correlating it with the observation data. The signal-based methods are based on statistical models established by means of machine learning and pattern recognition. The third approach is a hybrid approach. The hybrid methods use the physical models to supplement experimental data, derive efficient monitoring strategy and calibrate the signal-based models.

\subsection{Signal-based methods}

\subsubsection{Fuzzy logic}

The term 'fuzzy set' was introduced by Zadeh (1965). Recently it has found popularity in various applications. One of the potential application areas of fuzzy systems is the rock engineering classification systems (Bellman and Zadeh 1970; Nguyen 1985; Nguyen and Ashworth 1985; Juang and Lee 1990; Habibagahi and Katebi 1996; Gokay 1998; Sonmez et al. 2003). It has also been used for the construction of models for predicting rock mass and material properties (Grima and Babuska 1999; Finol et al. 2001; Kayabasi et al. 2003; Lee et al. 2003). Other researchers have used fuzzy set and systems for predicting machine performance depending on the properties of rock mass and material (den Hartog et al. 1997; Deketh et al. 1998;
Alvarez Grima and Verhoef 1999; Alvarez Grima et al. 2000; Basarir et al. 2007; Kucuk et al. 2011).

For example, Basarir et al. (2007) conducted complementary research work and presented an improvement of a previously published grading rippability classification system by the application of fuzzy set theory. The developed fuzzy based rippability classification system considers the utilization of the rock properties such as uniaxial compressive strength, Schmidt hammer hardness, the field p-wave velocity and the average discontinuity spacing, as well as the expert opinion. The fuzzy set theory was chosen mainly to deal with uncertainty and to eliminate bias and subjectivity. In the conventional set theory a given element can either belong or not belong to a set. Opposite to this, in the fuzzy modelling membership functions are used to provide transition from belong to a set to not belong to a set. Therefore, the passage is gradual rather than sharp as in the case of the conventional set theory. Designing membership functions is the most critical part of constructing fuzzy model. Each membership function uses linguistic terms such as very weak, weak, moderate, strong or very strong. These linguistic variables can be considered as the key for ill-defined systems. The input and output membership functions and the related linguistic terms of the constructed fuzzy model used to predict the rippability classes of rock masses are shown in Fig. 11. The links between input and output variables are connected by means of if-then rules i.e. "if seismic velocity is Fast (F) and uniaxial compressive strength is Strong (S) and discontinuity is Small (B) and Schmidt hammer is Very Hard ( $\mathrm{VH})$ then rating is Difficult (D)". At the final stage of modelling, the rules are compiled and a crisp value for the output parameters, in this case the rating, is obtained and the output class is defined.

The validity of the proposed fuzzy model was checked by the comparison against existing classification systems, direct ripping production values and expert opinions obtained at studied sites as shown in Table 1. The fuzzy logic based system yields the membership degree for the assed rippability class. Therefore, the developed system reduces the uncertainty and biased usage that appear in the existing classification systems.

More comprehensive and concise review on the rock engineering applications of fuzzy set theory was compiled in Adoko and Wu (2011). 
Fig. 11 Membership functions for input variables, uniaxial mocpressive strength (a), Schmidt hammer hardness (b), seismic velocity (c), discontinuity spacing (d) and output variable rating (e) (Basarir et al. 2007)

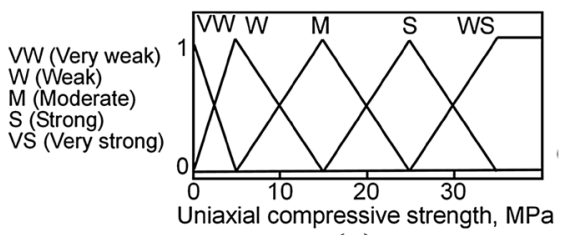

(a)

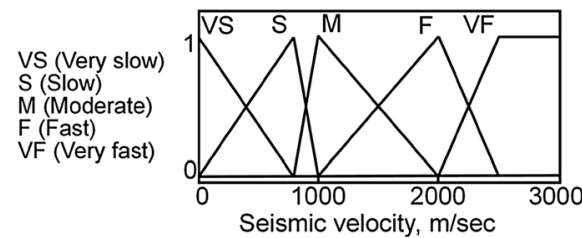

(c)

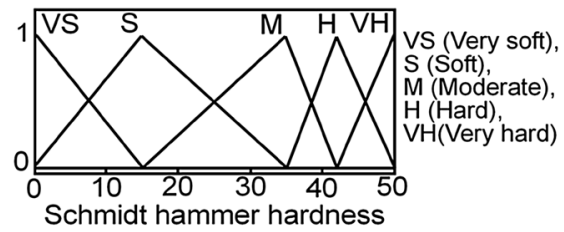

(b)

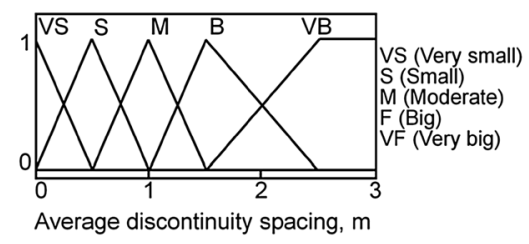

(d)

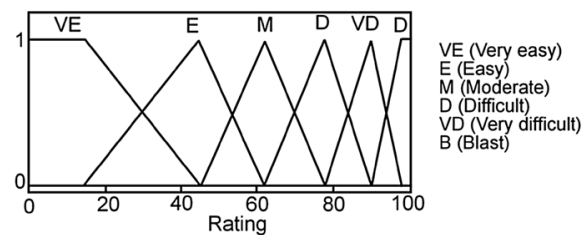

(e)

Table 1 Comparison of rippability classes of rocks by existing methods and constructed fuzzy model

\begin{tabular}{|c|c|c|c|c|c|c|c|}
\hline \multirow{2}{*}{$\begin{array}{l}\text { Studied } \\
\text { region/ } \\
\text { district }\end{array}$} & \multirow[t]{2}{*}{$\begin{array}{l}\text { Measured hourly ripper } \\
\text { production }\left(\mathrm{m}^{3} / \mathrm{h}\right)\end{array}$} & \multirow{2}{*}{$\begin{array}{l}\text { Weaver } \\
(1975) \\
\text { Class }\end{array}$} & \multirow{2}{*}{$\begin{array}{l}\text { Müftüoglu (1983) } \\
\text { Class }\end{array}$} & \multirow{2}{*}{$\begin{array}{l}\text { Singh et al. } \\
(1987) \\
\text { Class }\end{array}$} & \multicolumn{3}{|c|}{$\begin{array}{l}\text { Constructed fuzzy system (Basarir } \\
\text { et al. 2007) }\end{array}$} \\
\hline & & & & & Rating & $\begin{array}{l}\text { Membership } \\
\text { degree }\end{array}$ & $\begin{array}{l}\text { Class for } \\
\text { D8 dozer }\end{array}$ \\
\hline $\begin{array}{l}\text { Tuncbilek/ } \\
34 \text { Makina }\end{array}$ & 356 & $\begin{array}{l}\text { Extremely } \\
\text { hard ripping }\end{array}$ & $\begin{array}{l}\text { Marginal without } \\
\text { blasting }\end{array}$ & Difficult & 76 & 0.90 & Difficult \\
\hline $\begin{array}{l}\text { Tuncbilek/ } \\
\text { Omerler }\end{array}$ & 250 & $\begin{array}{l}\text { Extremely } \\
\text { hard ripping }\end{array}$ & Very difficult & Marginal & 88 & 0.81 & $\begin{array}{l}\text { Very } \\
\text { difficult }\end{array}$ \\
\hline $\begin{array}{l}\text { Tuncbilek/ } \\
18 \mathrm{PH}\end{array}$ & 1000 & $\begin{array}{l}\text { Very hard } \\
\text { ripping }\end{array}$ & $\begin{array}{l}\text { Difficult-very } \\
\text { difficult }\end{array}$ & Moderate & 52 & 0.60 & Easy \\
\hline $\begin{array}{r}\text { Tuncbilek/ } \\
\text { Kuspinar }\end{array}$ & 855 & $\begin{array}{l}\text { Very hard } \\
\text { ripping }\end{array}$ & $\begin{array}{l}\text { Very difficult- } \\
\text { extremely } \\
\text { difficult }\end{array}$ & Difficult & 65 & 0.76 & Moderate \\
\hline $\begin{array}{l}\text { Sivas- } \\
\quad \text { Kangal/ } \\
305\end{array}$ & 1350 & Hard ripping & Very difficult & Moderate & 20 & 0.85 & Very easy \\
\hline $\begin{array}{l}\text { Sivas- } \\
\text { Kangal/ } \\
310\end{array}$ & 330 & $\begin{array}{l}\text { Extremely } \\
\text { hard ripping }\end{array}$ & Very difficult & Difficult & 76 & 0.90 & Difficult \\
\hline
\end{tabular}

\subsubsection{Neural networks}

Neural network or ANN is a computational method used to acquire, represent and compute a mapping from a multivariate space of information to another specified set of data representing that mapping
(Garrett 1994; Singh et al. 2013). The ANN imitates human brain and nerve system, it consists of elements, each receives a number of inputs and generates single output without needing any predefined mathematical equations of the relationship between model input and model outputs. That is why the ANN is preferred over 
conventional mathematical models and has been used in many areas of engineering (Sawmliana et al. 2007; Shahin and Elchalakani 2008; Cevik et al. 2010; Cabalar et al. 2012; Singh et al. 2013; Alemdag et al. 2016).

\subsubsection{Adaptive neuro fuzzy inference system (ANFIS)}

The adaptive neuro fuzzy inference system (ANFIS) is one of the evolutionary modelling techniques. In fact, it is a combination of two widely used artificial intelligence methods namely the neural network and fuzzy logic. Each of these methods has its own advantages and disadvantages and the ANFIS combines the advantages of both of these methods. It takes the advantage of recognizing patterns and adapting the method to cope with the changing environment from neural networks and it takes the advantage of incorporating human knowledge and expertise to deal with uncertainty and imprecision taken from fuzzy logic. Due to these advantages, the ANFIS has been increasingly used in earth sciences in the applications complicated by high uncertainty (Gokceoglu et al. 2004; Singh et al. 2007; Iphar et al. 2008; Yilmaz and Yuksek 2009; Dagdelenler et al. 2011; Kucuk et al. 2011; Yilmaz and Kaynar 2011; Basarir et al. 2014; Asrari et al. 2015; Basarir and Karpuz 2016; Fattahi 2016).

Basarir et al. used one of the evolving soft computing methods, ANFIS, for the interpretation and analysis of the MWD (Measurement While Drilling) data for the prediction of Rock Quality Designation (RQD) (Basarir et al. 2017), percentage of drill core pieces in length of $10 \mathrm{~cm}$ or more. The input for the model consists of the most widely recorded and known drilling operational parameters such as bit load $(\mathrm{BL})$, bit rotation $(\mathrm{BR})$ and penetration rate $(\mathrm{PR})$. The sequential network architecture, Fig. 12a showing the structure of the model, membership functions and corresponding linguistic terms of input parameters of the developed ANFIS model are shown in Fig. 12b. Statistical performance indicators show that the ANFIS modelling is suitable for obtaining and quantifying complex correlations between the MWD parameters and geotechnical conditions, see Fig. 13. In this particular application a good correlation with the RQD was obtained. Initial estimation of the RQD can be obtained based on MWD parameters.
4.2 Model-based computational methods

\subsubsection{Finite element method}

For the last 50 years prediction of the behaviour of continuum mechanics systems, from geomechanics structures to human body organs, have been dominated by Finite Element Method (FEM) (Zienkiewicz 1965; Martin and Carey 1973; Zienkiewicz et al. 1977; Bathe 1996) that uses a computational grid in a form of mesh of interconnected triangular or rectangular elements for 2-D problems and tetrahedral or hexahedral elements for 3-D problems. Application of FEM in geomechanics started in the sixties of twentieth century (Anderson and Dodd 1966; Zienkiewicz and Cheung 1966; Zienkiewicz et al. 1966, 1968). It has been used in numerous computational geomechanics studies (Dysli 1983; Broyden 1984; Bardet 1990; Auvinet et al. 1996; Moresi et al. 2003; Yue et al. 2003; Kardani et al. 2013) with important contributions from O.C. Zienkiewicz, one of the founders of finite element method (Zienkiewicz et al. 1970, 1999) (Pastor et al. 2011).

Despite the progress achieved and the development of specialised finite element procedures for computational geomechanics (Broyden 1984; Auvinet et al. 1996; Moresi et al. 2003; Kardani et al. 2013), significant challenges (or even limitations) associated with finite element discretisation in geomechanics have been recognised (Zhang et al. 2000; Yue et al. 2003; Luan et al. 2005; Zhao et al. 2011; Kardani et al. 2013; Komoroczi et al. 2013; Pramanik and Deb 2015; Zhou et al. 2015b). These include: (1) Tedious and time consuming creation of finite element meshes of geological structures with complex geometry. Although such creation has been a subject of significant research effort, the existing solutions require water-tight surface defining the geometry. This is a challenge on its own as, unlike in typical engineering applications where such surfaces are defined using $\mathrm{CAD}$, in geomechanics they typically need to be extracted from images and other geological data; (2) Accounting for large deformations/strains that geological structures may undergo (e.g. due to landslides, earthquakes etc.) typically require computationally expensive remeshing when the solution accuracy deteriorates due to element distortion; (3) Discontinuities due to fragmentation, cracks and geological faults remeshing typically require remeshing to ensure 


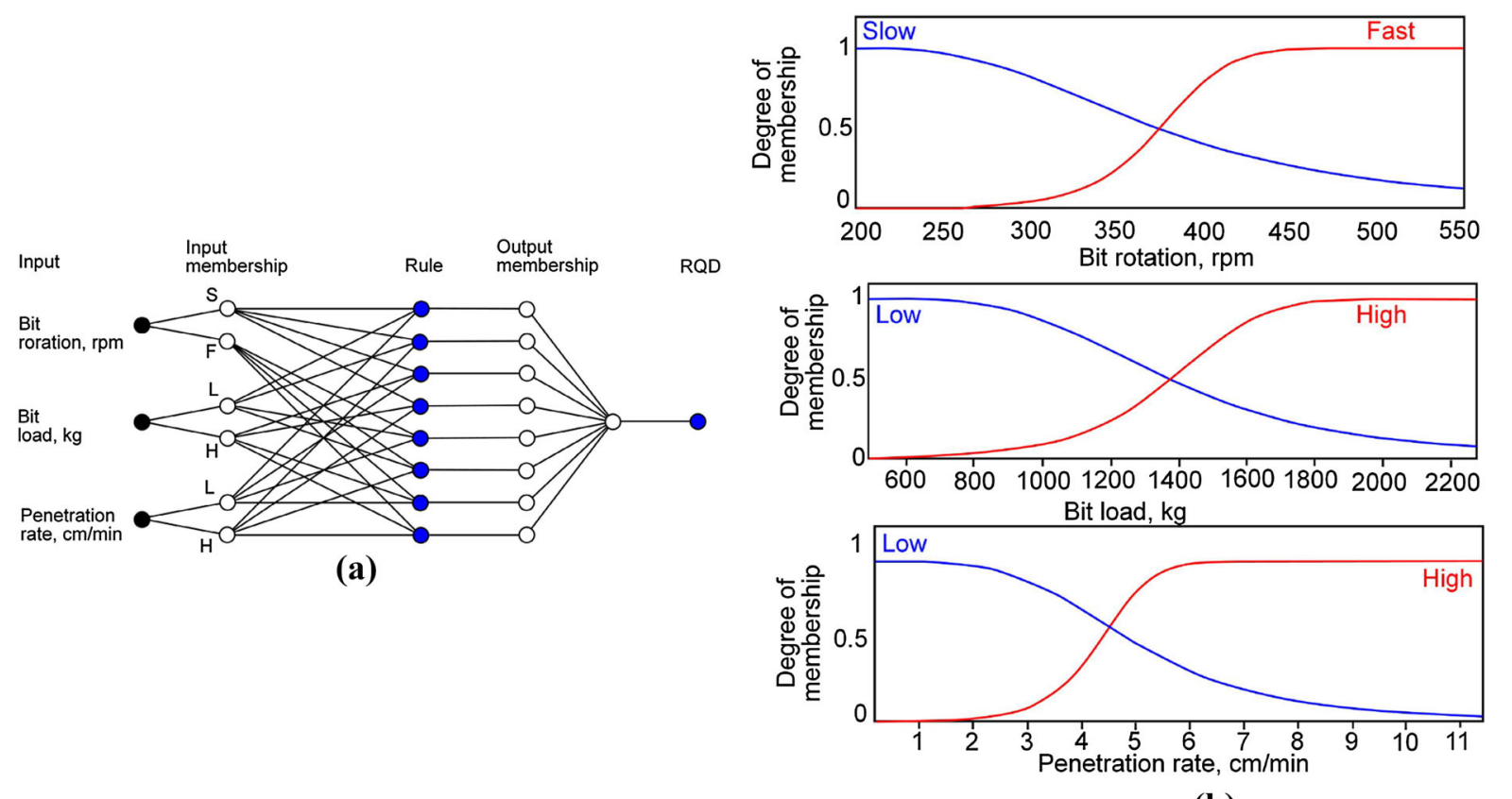

(b)

Fig. 12 Sequential network architecture (a) and membership functions (b) for the constructed ANFIS model in Basarir et al. (2017)
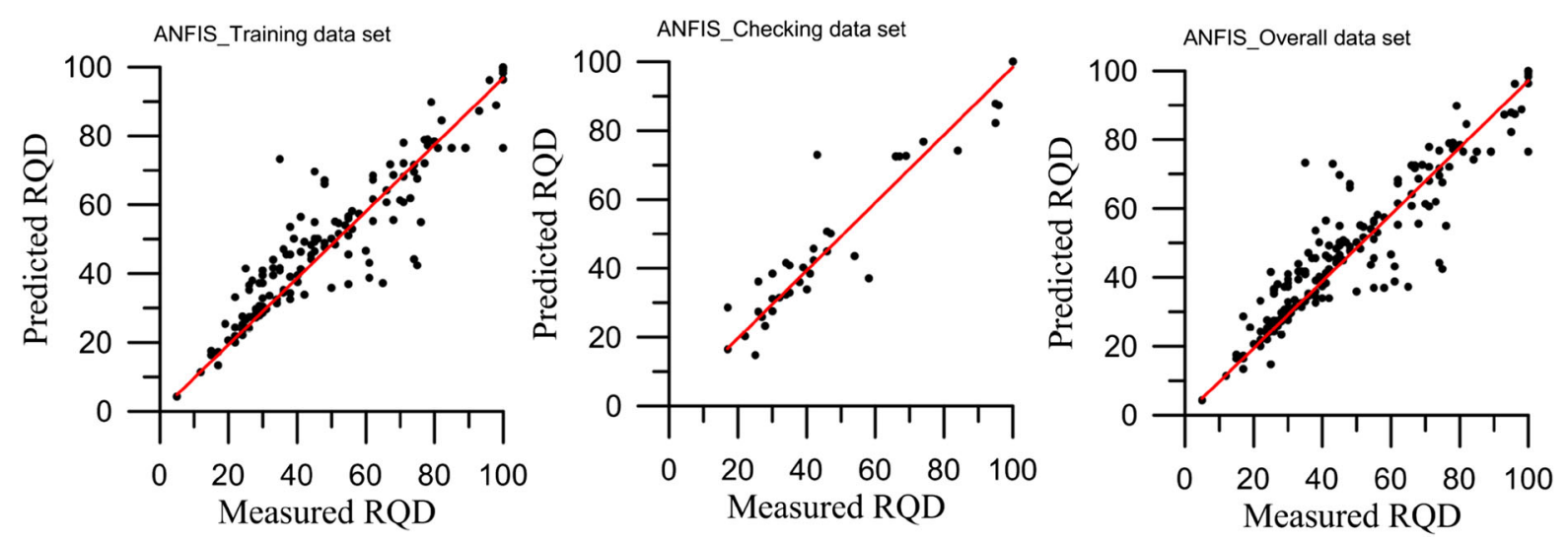

Fig. 13 Correlations between measured and predicted RQD values (Basarir et al. 2017)

solution convergence in the crack area and to introduce changes to the computational grid to account for formation of crack/discontinuity; and (4) Modelling of fluid flow through soil and other geological structures.

To overcome these challenges, methods that do not rely on finite element discretisation have been proposed. This includes discrete element methods (DEM) and meshless (also referred to as mesh-free and element-free) methods.

\subsubsection{Discrete element method}

Discrete Element Method (DEM), also referred to as Distinct Element Method have been introduced by Cundall and Strack (1979) to model the mechanical behaviour of granular materials. The main ingredients of a discrete element model are the scheme that integrates the equations of motion of each particle and the interaction forces that govern the inter-particular contacts. The original version that Cundall and Strack developed uses rigid discs or spheres to model the 
individual elements, but more complex shapes have also been introduced by Karrech et al. (2008), Tao et al. (2010), Lu et al. (2015). As discontinuities/ fragmentation in DEM can be produced through the loss of adhesive contact between the particles, the DEM has been regarded by some researchers as an effective tool for modelling of rocks undergoing cracking/fragmentation (Onate and Rojek 2004; Azevedo and Lemos 2006; Komoroczi et al. 2013) and layered and granular geological materials (Kruggel-Emden et al. 2007; Buechler et al. 2013). One of the key difficulties is that the desired macroscopic constitutive behaviour cannot be defined directly, but needs to be obtained by formulating an appropriate contact (force-displacement and damping or friction) law that governs interactions between the particles. In practice, this process tends to involve extensive calibration where the contact law input parameters are derived by quantitative comparison between the modelling and experimental results (Marigo and Stitt 2015). Changes in the type of load acting on the analysed medium may require new calibration; in particular modelling of viscous behaviour poses a major challenge (Komoroczi et al. 2013). Another major limitation of DEM modelling is its demand on computational time. Computational procedures to accelerate convergence under repeated loading conditions have been suggested (Karrech et al. 2007). Parallel computing offers new horizons for efficient DEM modelling with large numbers of degrees of freedom (Shigeto and Sakai 2011).

\subsubsection{Meshless methods of continuum mechanics}

Meshless methods are a family of methods of computational mechanics where the equations of continuum mechanics are spatially discretised over the analysed domain using a cloud of nodes (where forces and displacements are calculated) with no assumed structure on the interconnection between the nodes.

Smoothed particle hydrodynamics $S P H$ is regarded as the first meshless method. It utilises a strong form of equations of continuum mechanics (Gingold and Monaghan 1977; Lucy 1977; Monaghan 1992). The SPH (often in combination with DEM) has been applied in geomechanics to model ductile failure and hydrofracturing (Komoroczi et al. 2013), rock blasting (Fakhimi and Lanari 2014), intersecting discontinuities and joints in geomaterials (Pramanik and Deb
2015), fast landslides (Clearly and Prakash 2004; Pastor et al. 2011), geophysical flows (Clearly and Prakash 2004) and fluidised soils (Rodriguez-Paz and Bonet 2005; Pastor et al. 2009). However, several important shortcomings of the SPH method such as instabilities in tension and the accuracy inferior to that of the finite element method, have been recognised in the literature (Belytschko et al. 1996). Therefore, substantial research effort has been devoted to meshless methods that utilise the Galerkin weak form of equations of continuum mechanics.

Meshless (element-free) Galerkin methods use the Moving-Least Squares (MLS) shape functions, while the spatial integration is typically conducted over a background grid that does not have to conform to the boundary of the analysed continuum (Belytschko et al. 1994, 1996, 1997). The nodes where the displacements are calculated are independent of the background grid (Belytschko et al. 1996; Murakami et al. 2005; Horton et al. 2010). This separation of the interpolation and integration grids allows for almost arbitrary placement of the nodes throughout the analysed continuum, which is well suited for automated generation of computational grids for complicated geometries. However, restrictions on the ratio of the number of integration points and nodes apply (Horton et al. 2010). An alternative approach is to use the nodes as vertices of the integration cells. Although this approach has been used in some commercial codes (Hallquist 2005), it imposes finite element-like constraints on the positions of the nodes and, therefore, is not regarded as a method of choice in the Galerkintype meshless discretisation, see Fig. 14.

As MLS shape function facilitate smooth interpolation of displacement and pressure fields, Galerkintype meshless methods can be applied to solving problems that require modelling of soil-water coupling problems (Murakami et al. 2005). Introducing discontinuities/cracks in such methods is accomplished through a modification of the influence domains of the affected nodes (the nodes located on the opposite sides of the discontinuity cannot interact with each other) using either visibility criterion (Belytschko et al. 1996; Jin et al. 2014) or manifold method (Shi 1992) without any changes to the computational grid. Therefore, the Galerkin-type meshless methods have been applied in modelling of damage of rocks with pre-existing/initial cracks (Luan et al. 2005)and crack propagation in brittle rocks 


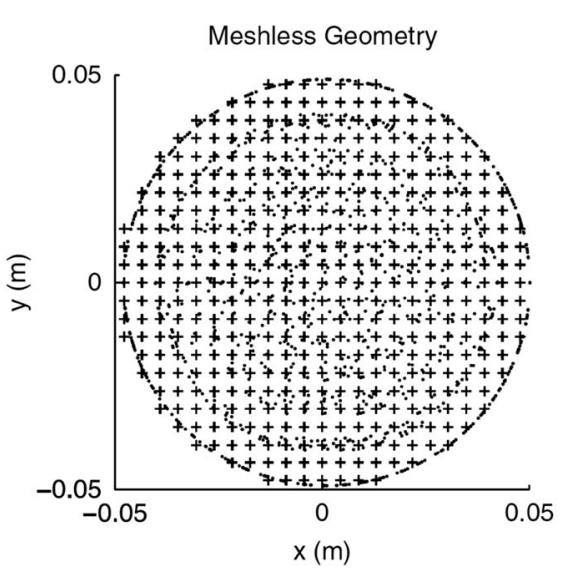

Fig. 14 Meshless discretisation of a cylinder (diameter of $0.1 \mathrm{~m}$ and height of $0.1 \mathrm{~m}$ ) with almost arbitrarily placed nodes (.) and regularly background integration points $(+)$. In this discretisation, the number of integration points is two time

(Zhang et al. 2012a) and concrete (Belytschko et al. 2000) as well as ductile (Simkins and $\mathrm{Li}$ 2006) materials.

Although the MLS shape functions and background spatial integration facilitate versatility and robustness of Galerkin-type meshless methods, they are also encounter some challenges. As the MLS shape functions do not have the ideal Kronecker delta properties, they introduce inaccuracies when imposing essential boundary conditions. To overcome this challenge, coupling of meshless and finite element discretisation with essential boundary conditions imposed through finite element shape functions (Belytschko et al. 1996; Krongauz and Belytschko 1996; Zhang et al. 2014) and Lagrange multipliers (Belytschko et al. 1994, 1996) have been used. Recently Chowdhury et al. (2015) proposed and verified application of Modified Moving Least Squares (MMLS) with polynomial (quadratic) bases (Joldes et al. 2015a) and regularised weight functions for imposition of essential boundary conditions within the Galerkin-type meshless computation framework. As the MLS shape functions are not polynomials and their local support may not align with the integration cells, background integration using Gaussian quadrature may prove difficult to quantify errors. Unlike in Finite Element Methods, where the shape functions are polynomials, Gaussian quadrature that guarantees accuracy of the integration cannot be apriori selected. Gaussian adaptive integration scheme has been proposed to overcome this challenge (Joldes et al. 2015b).

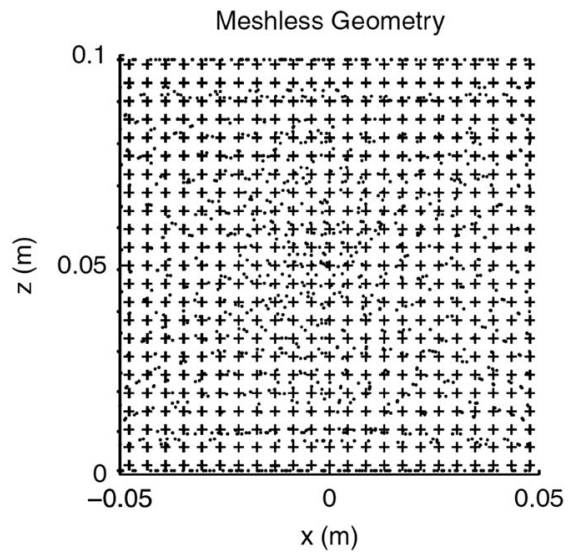

greater than the number of nodes where the displacement is computed. Only 2D orthogonal views are provided as 3D visualisation results in a very unclear cloud of points (Horton et al. 2010)

For example, Fig. 15 presents a meshless (element free) Galerkin type computational model for a cantilever beam (length $\mathrm{L}=48 \mathrm{~mm}$, depth $\mathrm{D}=12 \mathrm{~mm}$ ) subjected to bending due to parabolically varying traction $\mathrm{P}=1000 \mathrm{~N}$ acting on the left-hand-side edge of the model. The right-hand-side edge is rigidly constrained. Detailed description of this example is provided in Chowdhury et al. (2017). The model was implemented using Meshless Total Lagrangian Explicit Dynamics (MTLED) method developed by Horton et al. (2010), Chowdhury et al. (2015), Joldes et al. (2015a, c) with the Modified Moving Least Square (MMLS) shape functions. The essential boundary conditions (at the rigidly constrained edge of the beam) were imposed using recently developed Essential Boundary Conditions Imposition in Explicit Meshless (EBCIEM) method by Joldes et al. (2017). Adaptive Dynamic Relaxation algorithm by Joldes et al. (2011) was applied to ensure convergence to the steady (static) state. To facilitate accurate spatial integration, a very dense background integration grid consisting of 2500 rectangular integration cells $(100 \times 25$ grid $)$ was used. $10 \times 10$ Gauss quadrature was applied in each integration cell.

The results indicate a very good agreement between the deformations computed using the meshless method (MTLED) and analytical solution by Timoshenko and Goodier (1970). The maximum differences are below $0.1 \%$ of the beam deflection.

As already mentioned, although the Galerkin-type meshless methods facilitate almost arbitrary 

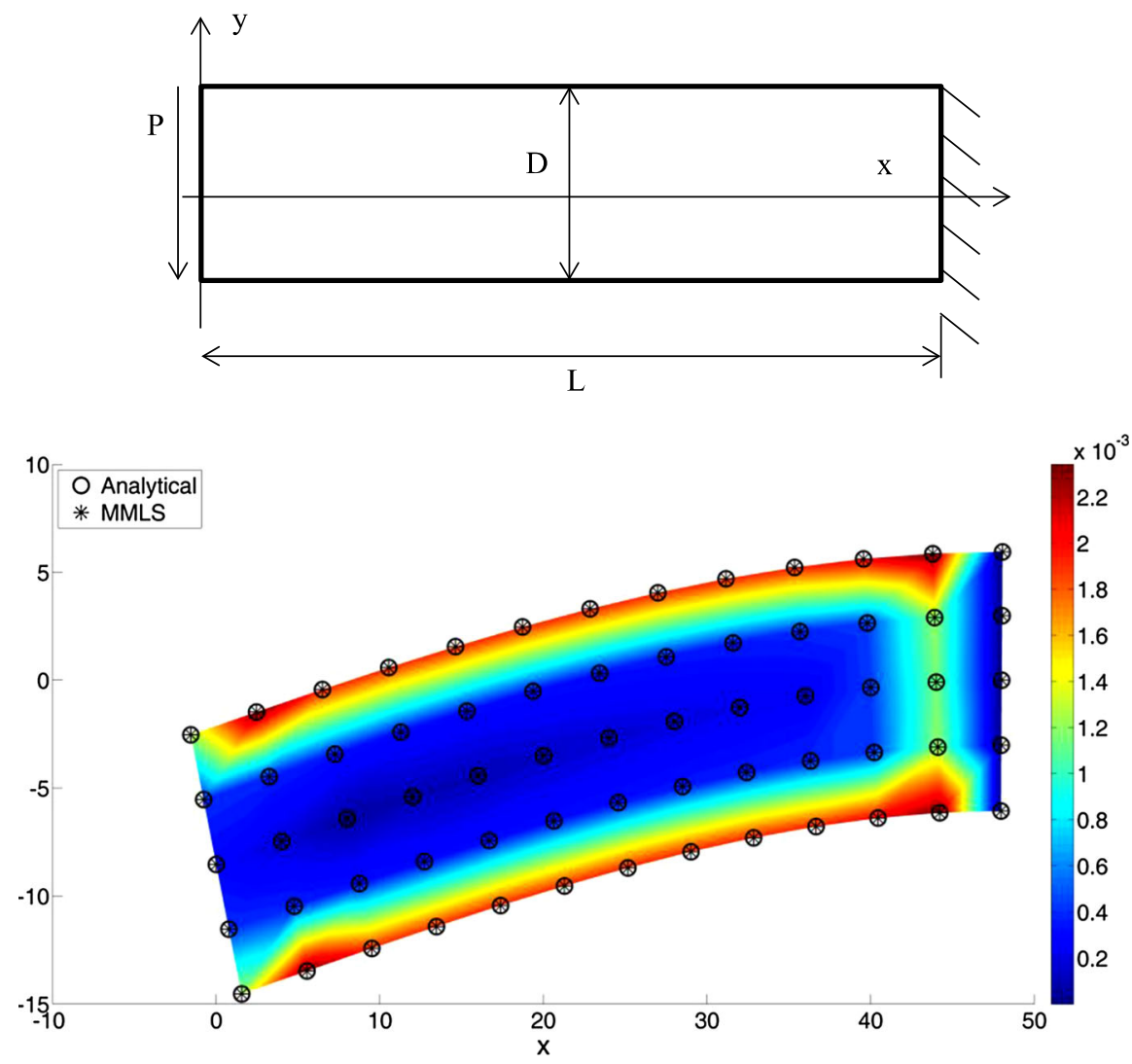

Fig. 15 Computation of deformations of cantilever beam subjected to bending using Galerkin-type Meshless Total Lagrangian Explicit Dynamics (MTLED) method developed by Horton et al. (2010), Chowdhury et al. (2015), Joldes et al. (2015a, c), Chowdhury et al. (2017) with the Modified Moving Least Squarse (MMLS) shape functions by Chowdhury et al. (2017). The figure shows the differences (in $\mathrm{mm}$ ) between the

placement of the nodes throughout the analysed continuum, restrictions on the ratio of the number of integration points and nodes (Horton et al. 2010) form constraints on automated grid generation. Although overcoming these restrictions (i.e. making meshless computational grids to provide stable and converged results for any placements of the nodes) still remains an unsolved challenge, modification of the MLS shape functions and adaptive integration proposed by Joldes et al. $(2015 \mathrm{a}, \mathrm{b})$ may be regarded as the first step in providing the solution. The ultimate outcome can be the capability to create computational geomechanics models directly from images of geomaterials and geological structures-a concept used by Yue et al. (2003) for creation of finite element models of geomaterials. Effectiveness of a very similar approach analytical solution from Timoshenko and Goodier (1970) and the deformations computed using MTLED. For the beam deflection of $3 \mathrm{~mm}$, the maximum differences are below $2.5 \times 10^{-3} \mathrm{~mm}$. The beam length $L=48 \mathrm{~mm}$, depth $D=12 \mathrm{~mm}$, force $P=1000 \mathrm{~N}$, Young's modulus $E=3000 \mathrm{~Pa}$, Poisson's ratio $v=0.3$, and force $P=1000 \mathrm{~N}$

(neuroimage as a computational models) has been proven in biomedical engineering when creating human body organ models for surgical simulation (Zhang et al. 2012b, 2013).

\subsubsection{Isogeometric analysis}

As discussed above, creating finite element meshes for computational geomechanics models includes extraction of geometry from images and then generation of the actual mesh. Geometry representation obtained through segmentation differs from that in the finite element analysis. This not only makes mesh generation difficult and often tedious, but also leads to inaccuracies as the mesh only approximates geometry extracted from the images. This problem is not limited 
to computational geomechanics. It has been recognised as a major challenge in biomedical engineering where patient-specific computational biomechanics models need to be created from medical images (Wittek et al. 2016). Hughes et al. (2005) pointed to the fact that differences in geometry representation in the Computer Aided Design (CAD) systems and finite element analysis lead to excessively long time (up to $80 \%$ of the entire analysis time) devoted to mesh generation in major engineering applications. In the isogeometric analysis, this problem is solved by eliminating the finite element polynomial representation of geometry and replacing it with the representation based on NURBS (Non-Uniform Rational B-Splines) (Hughes et al. 2005) which is a standard technology used in CAD systems. This implies creation of NURBS elements that exactly represent the geometry and facilitate direct translation of CAD geometric model to computational model. Isogeometric analysis has been applied in geomechanics in modelling of unsaturated flow in soils (Nguyen et al. 2014) and domains that contain inclusions exhibiting elasto-plastic behaviour (Beer et al. 2016). The necessity to create surfaces (represented by NURBS) remains a major limiting factor in application of isogeometric analysis in situations where the CAD geometric models are not readily available.

\subsubsection{Inverse methods}

Inverse modelling is a vast research area, which is applicable to every engineering discipline. In this paper, we mainly focus on aspects that are related to computational monitoring. Unlike forward modelling approaches, the inverse modelling is data-driven (Zhang et al. 2015). While a forward model is typically used in the design phase to make early decisions and facilitate pre-feasibility studies, the inverse modelling accompanies the service life of the structure. The inverse modelling takes the monitored behaviour data as inputs, expresses them as driving variables in a mathematical, empirical or numerical model and delivers predictions on efficiency, sustainability, stability and so on. Among the comprehensive reviews that are related to inverse problems in computational modelling of mechanical and civil engineering systems, it is worthwhile mentioning the work of Friswell and Penny (1992) presented an overview of inverse methods for damage location and detection. Inverse models have been used in civil engineering applications for the energy saving and control in modern buildings (Heo and Zavala 2012), fault detection and diagnosis in building management systems (Yoshida et al. 2001), modelling of leakage through a rockfill dam foundation (Zhou et al. 2015a), and monitor fatigue in steel bridge decks (FarrerasAlcover et al. 2017). In resource engineering, inverse approaches have been used to model variable density water flow (Bastani et al. 2010), investigate aquifer behaviour through pumping data (Samuel and Jha 2003), produce a data-driven approximation of the implicit relation between transmissivity and hydraulic head (Garcia and Shigidi 2006), design up-scaled borehole facilities for thermal energy storage (Tordrup et al. 2017), and health monitor offshore jacket platforms (Haeri et al. 2017).

Despite their pertinence, the inverse methods have not been widely accepted yet as they involve considerable costs associated with sensor networks, data management and computing time (Bosse and Lechleiter 2016). One of the other major drawbacks of the inverse modelling is the non-uniqueness of solution, which can hinder their applicability (Dietrich and Newsam 1990; Jing et al. 2007). With the progress of numerical techniques and the appetite for new technologies, the general public may embrace inversemodelling-based techniques with the warmth they deserve in the near future.

\subsection{Measurement and system identification}

Derivation of meaningful information from a measurement primarily depends upon the choice of a suitable identification system and data analysis method. In general, the signal-based analysis methods are able to process direct and indirect measurements. When the signal based methods are used, the measurement obtained directly from strain gauges, photogrammetric methods and embedded smart sensors do not require prior parameter estimation, see Fig. 1.

Sensor placement is a major challenge of monitoring systems. The design of sensor network and types of sensors used are usually based on preliminary analysis or experiments, which in turn calls for accurate analytical or numerical models, such as the finite element, discrete element or meshless methods. The photogrammetry methods, on the other hand, do not require prior analysis and can be used wide field 
measurements. For example, the digital image correlation (DIC) is often applied for analysis of nonhomogeneous and highly anisotropic materials. DIC is also compatible with the FEM, which facilitates verification of both measurements and calculations.

Combination of several techniques can lead to new monitoring systems. For instance, smart embedded sensors can be used as embedded actuators for acoustic and electromagnetic emission. The analysis of such systems will require the model based methods. The combination of direct and indirect measurements and analysis methods into a monitoring system can be best demonstrated by rotary borehole drilling.

\subsubsection{Monitoring of rotary borehole drilling}

The ultimate goal of the real time drilling monitoring is the optimisation of the rate of penetration (ROP) at the specific drill bit-rock interface. A typical borehole rotary drilling system consists of a drill string made of thin-walled pipes or coiled tubing, a bottom hole assembly (BHA) and a drill bit at the end. The drill bit is either rotated by a downhole motor or the torque transmitted from a top rotary drive by the drill string. The revolving drill bit crushes and cuts the rock under applied weight-on-bit and penetrates downwards. A drilling fluid so-called drilling mud is pumped down through the drill string and circulated back to surface through the annulus (a space between the borehole and the drill pipes).

The drilling process is monitored through direct and indirect monitoring of downhole conditions. In the indirect monitoring, the downhole conditions are inferred based on the surface measurements, such as rotary speed and torque, force at the top of drill string, flow rate and pressure of the drilling mud, while the direct monitoring uses the measurements obtained while drilling (MWD) using the sensors attached to BHA. The solids content, viscous properties and gas content of the circulated drilling mud is also analysed to complete the reconstruction of the downhole conditions. Properties of the drilled formation are evaluated in real time as well through formation testing while drilling (FTWD) and seismic while drilling (SWD) procedures.

MWD systems consist of three components: a power system, a telemetry system, and a directional sensor. The drilling-mechanics parameters commonly measured downhole are drilling fluid pressure, weight- on-bit (WOB), torque-on-bit (TOB), temperature, and well size. The systems for transmitting MWD information to the surface include (Poletto and Miranda 2004): (1) Mud pulse telemetry that utilises pressure waves in the drilling fluid, (2) Electromagnetic radiation that uses electromagnetic guided waves travelled in the formations, (3) Acoustic telemetry that is based on the stress wave propagation along the drill string (Drumheller 1989; Carcione and Poletto 2000), (4) Wired pipe telemetry is the latest technology that uses insulated conducting cables embedded into the drill pipe to directly transmit the signal (Veeningen 2011; Pixton et al. 2014; Shishavan et al. 2016).

The surface measurements are correlated with MWD data using data based (Macpherson et al. 2001; Finger et al. 2003) and model based (Tahmeen et al. 2014) interpretation methods. FTWD provides the data for assessment of pore pressure (Ma et al. 2015). SWD uses the drill bit as a source for the seismic imaging of the formation ahead the drill bit (Poletto and Miranda 2004). A range of physical and phenomenological models is used for monitoring of bit-rock interaction (Detournay et al. 2008; Chiaia et al. 2013), detection of stick-slip vibrations (Zhu et al. 2014), and modelling of drilling fluids (Guzek et al. 2015),

For example, a computational tool developed by Petrobras is able to monitor the real time drilling conditions by comparing the pressure while drilling (PWD), torque and drug predicted based on the mud analysis to the real-data obtained from MWD measurements (Gandelman et al. 2013).

\section{Computing in real time}

\subsection{Real time computation on commodity hardware: graphic processor units (GPUs)}

Although as discussed in the previous section, high performance computing utilising supercomputer and processor clusters has been used in numerous applications in geomechanics, it requires expensive hardware infrastructure. This prompted computational mechanics community to turn attention to Graphics Processing Units (GPUs) that offer high computation power and increased memory bandwidth at a relatively low cost (Joldes et al. 2010; Allard et al. 2012; 
Georgescu et al. 2013; Huthwaite 2014; Kardani et al. 2015; Strbac et al. 2015)—over $3 \times 10^{3}$ computing cores in a GPU costing around $\$ 6000$. Application of GPU alone does not guarantee improvement in computational speed. GPUs have a highly parallel, multithreaded, many-core-processor architecture. This benefits problems that can be expressed as dataparallel computations with high arithmetic intensity, where the same program is executed on many data elements in parallel (Joldes et al. 2010).

Introduction of Compute Unified Device Architecture CUDA parallel programming platform and programming model by NVIDIA in 2006 and Open Computing Language (OpenCL) in 2008 has facilitated high level programming for general purpose computations on GPU. However, ensuring that the problems to be solved and related algorithms are formulated in a way that can benefit from parallel, multithreaded, many-core-processor architecture of GPU, may involve substantial research effort that may utilise a combined CPU-GPU approach with only a part of the algorithm implemented and executed on GPU and the rest computed on CPU. This is particularly the case for problems that involve solving large system of equations and may require substantial internal memory as indicated in the study on application of GPU-accelerated computations for large 3-D problems in geomechanics by Kardani et al. (2015). In contrast, finite element and meshless algorithms with explicit integration in time domain discussed in Sects. 4.2.1 and 4.2.3 are well-suited for GPU implementation as they do not involve solving systems of equations and have low internal memory requirements. As indicated in Joldes et al. (2010), GPU implementation of such algorithms can increase computational speed by more than 20 times.

\subsection{Cloud computing}

Real time computational monitoring is no longer limited by computing power thanks to the introduction of low-cost on-demand cloud computing platforms, such as Amazon Web Services, Microsoft Azure and Google Compute. Adopting cloud technologies can radically improve real time monitoring by allowing hundreds of different computational scenarios to be explored simultaneously across a platform of virtual machines. Data can be stored in scalable object storage systems or data bases. Communication technologies can be used to provide real time alerts to warn of impending issues via smart phones. Fault tolerance can be built into the system by distributing computation infrastructure accross physically isolated data centers, meaning that system downtime can be avoided.

\section{Applications: geotechnical examples}

One of the earliest applications of computational monitoring in real time in geotechnical engineering is one that assists rapid and safe construction of embankments founded on soft clay. These embankments are built using compacted soil and are typically up to $15 \mathrm{~m}$ in height for road embankments and often over $30 \mathrm{~m}$ high in tailings dam constructions. Immediate application of the additional embankment load to the foundation clay would cause the embankment to collapse by inducing a bearing capacity failure in the clay. To avoid such a collapse, the embankment is often built up in stages so that the clay can gain additional shear strength through consolidation under a given stage before application of the next stage. Engineers need to monitor the excess pore pressures in the foundation soil during construction so that an assessment can be made of its strength and a decision made on when the next embankment stage can be added. Major savings in programme (and hence cost) can be achieved by proper integration of the pore pressures measured in real time and the numerical model employed for stability analysis. Pore pressures are now generally monitored using transducers operating on a vibrating wire principle (the data from which can now be recorded digitally). Settlement plate data and lateral deformations (inferred from tilts measured in inclinometer tubes) are also used to check that the embankment response is in keeping with the numerical model.

The example illustrated in Fig. 16 can be classed as one in which the observational method, as described by Peck (1969), is applied. This method has proved to be very popular as it enables most-probable conditions to be employed in the design rather than adopting pessimistic or very safe parameters. Carefully located instrumentation is monitored continuously and compared on an ongoing basis against the design assumptions and predictions. Examples of commonly used instrumentation in geotechnical engineering are: 


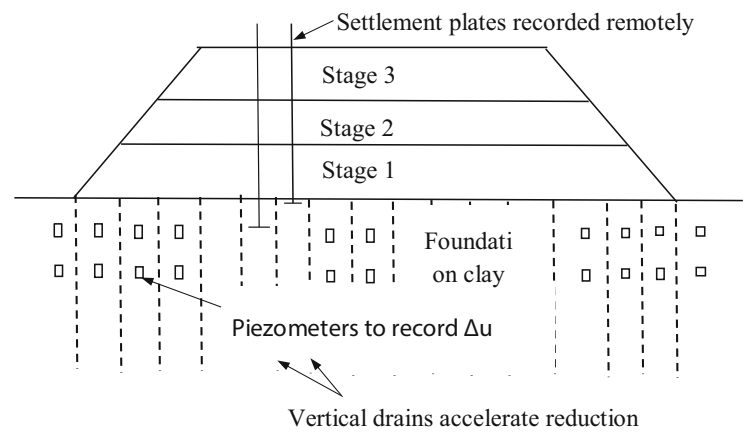

Fig. 16 Typical configuration for multi-stage embankment construction

- Extensometers to measure vertical strains in the ground and inclinometer to measure the distortion of the ground

- Pore pressure transducers, as shown in the example in Fig. 16

- Strain gauges on steel beams and reinforcement to measure strain and infer axial loads and bending moments

- Survey targets monitored by a total station to measure displacements

- Permanent loads cells on anchors and within structures.

- Earth pressure cells

The observational method requires initial estimation of 'trigger values' for critical parameters (e.g. displacement rate, strain rate) which, if exceeded, require the contractor to action contingency plans that had been agreed to at the outset of the project. Such contingency plans could, for example, include the installation of additional bracing struts for a deep basement excavation, removal of soil near the crest of a slope and strengthening of pile foundations using a raft. The observational approach provides an understanding to designers of how their designs are behaving and improves their general appreciation of the accuracy levels of their calculations. The presence of instrumentation can sometimes shed light on a problem that was not previously anticipated. One such example is shown on Fig. 17, which plots the measured variation of axial load and temperature in steel struts used to provide support to sheet pile wall excavation in Perth, Western Australia (Zaremba and Lehane 2007). This showed that the forces in the struts increased by $30 \%$ as the temperature increased by 25 degrees. The sheet pile was also moved inwards and outwards as the temperature and strut loads cycled. The information on Fig. 17 provided an explanation to the Contractor for why a settlement trough was developing on the active side of the wall outside of the excavation. Since completion of that project, the Contractor now paints all steel bracing white to minimise their temperature fluctuations in climates such as that in Western Australia.

Geotechnical monitoring can be used as a means of postponing future remediation work or cancelling it completely. One example is shown on Fig. 18 for a case where pillar settlement in a room and pillar mine lead to instability of the underground openings and progressive settlement of an overlying road. The mining company adopted a strategy of numerical modelling supported by on-going monitoring of the settlement. The numerical simulation include effects of strain softening in the rock material in the roof of the openings as well as the softening of the mudstone in which the pillars were located (which was observed when de-watering pumps were switched off in the mid-1990s). The numerical simulations predicted that there would not be a catastrophic collapse of the overlying road and the mine opening would close gradually. However, this prediction needed to verified using instrumentation. Results such as those presented in Fig. 18 enabled continual updating and improvement of the numerical simulation and gave greater confidence regarding the safety of the road. Ultimately, this approach brought very large cost savings to the mining company.

\section{Conclusions}

In this review paper, we have established the basic principles for the computational monitoring in real time. We have defined the computational monitoring as hybrid monitoring approach, which combines continuous measurement with real time interpretation and prediction. We perceive the computational monitoring as the next step in the development of intelligent engineering systems that have an integrated ability to monitor their working conditions, predict failures and control their performance.

We have shown that the methods of traditional monitoring in different fields of engineering have common features and similar challenges associated with the incorporation of data from different types of 
Fig. 17 Temperature and axial load variations in a steel strut bracing a sheet pile wall

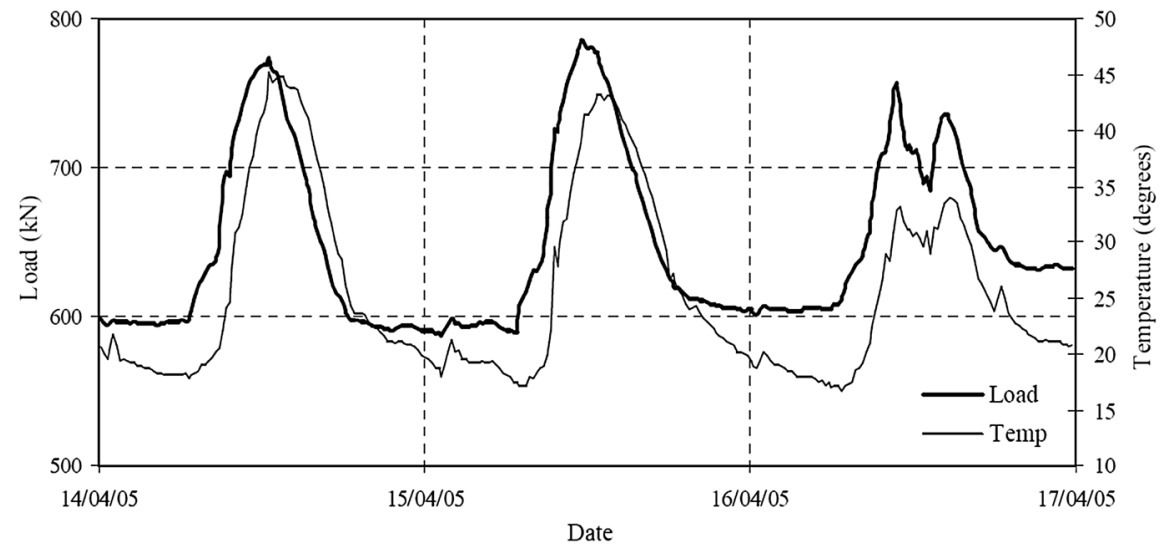

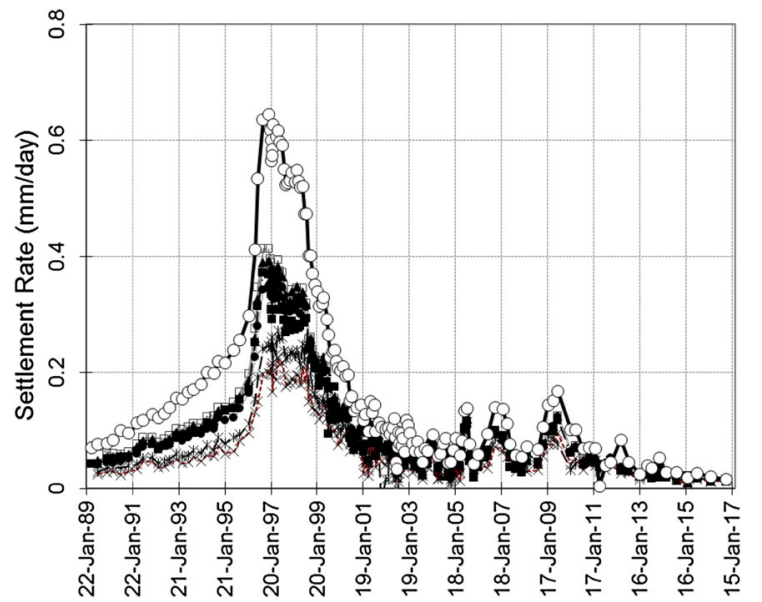

Fig. 1830 years of settlement monitoring due to collapse of an underground mine

measurement. We have also reviewed the measurement procedures and the computational models suitable for the continuous monitoring of various engineering systems. The review is concluded by the examples from the area of geotechnical engineering.

We expect that this review will initiate the exchange of ideas and cross-fertilisation between monitoring methods being developed in different areas of engineering and will assist in addressing the challenges in computational monitoring, some of which are:

- Progressive damage accumulation alters the basic characteristics of the monitored system, such as stiffness, energy dissipation, and etc. The challenge is to ensure continuous and often real time adjustment of the interpretation models to adopt to the system changes. This is especially important for vibration, acoustic emission and electromagnetic emission based data acquisition with the model based analysis.

- Design of the required measurement system and sensor networks before deployment is a significant challenge for computational monitoring system. The interpretation models must be capable of adapting to the changes in the measurement system, cd for instance by random sensors failures.

- Development of correlation models between signal-based and model-based interpretation methods is another challenge. Such models are needed to ensure the robust monitoring procedures.

- The major challenge is the prediction of global system behaviour based on local observations. Meeting this challenge would involve the development of adequate models of the global behaviour that would incorporate the local models interpreting the particular measurements.

Acknowledgements The authors acknowledge the financial support from the Faculty of Engineering and Mathematical Sciences of the University of Western Australia.

Open Access This article is distributed under the terms of the Creative Commons Attribution 4.0 International License (http:// creativecommons.org/licenses/by/4.0/), which permits unrestricted use, distribution, and reproduction in any medium, provided you give appropriate credit to the original author(s) and the source, provide a link to the Creative Commons license, and indicate if changes were made.

\section{References}

Adler L (1970) Evaluating double elasticity in drill cores under flexure. Int J Rock Mech Min Sci 7:357-370. https://doi. org/10.1016/0148-9062(70)90033-1 
Adoko AC, Wu L (2011) Fuzzy inference systems-based approaches in geotechnical engineering-a review. Electron J Geotech Eng 16:1543-1558

Alemdag S, Gurocak Z, Cevik A, Cabalar AF, Gokceoglu C (2016) Modeling deformation modulus of a stratified sedimentary rock mass using neural network, fuzzy inference and genetic programming. Eng Geol 203:70-82. https:// doi.org/10.1016/j.enggeo.2015.12.002

Allard J, Courtecuisse H, Faure F (2012) Chapter 21-Implicit FEM solver on GPU for interactive deformation simulation. In: Wenmei WH (ed) GPU computing gems, Jade edition. Morgan Kaufmann, Boston, pp 281-294. https:// doi.org/10.1016/b978-0-12-385963-1.00021-6

Alvarez Grima M, Verhoef P (1999) Forecasting rock trencher performance using fuzzy logic. Int J Rock Mech Min Sci 36:413-432

Alvarez Grima M, Bruines P, Verhoef P (2000) Modeling tunnel boring machine performance by neuro-fuzzy methods. Tunn Undergr Space Technol 15:259-269

Anderson HW, Dodd JS (1966) Finite element method applied to rock mechanics. In 1st ISRM Congress, 1 Jan 1966. International Society for Rock Mechanics

Annamdas VGM, Radhika MA (2013) Electromechanical impedance of piezoelectric transducers for monitoring metallic and non-metallic structures: a review of wired, wireless and energy-harvesting methods. J Intell Mater Syst Struct 24:1021-1042. https://doi.org/10.1177/ 1045389X13481254

Asrari A, Shahriar K, Ataeepour M (2015) The performance of ANFIS model for prediction of deformation modulus of rock mass. Arab J Geosci 8:357-365

Auvinet G, Bouayed A, Orlandi S, Lopez A (1996) Stochastic finite element method in geomechanics. Uncertainty in the geologic environment: from theory to practice. In: Vols 1 and 2: proceedings of uncertainty ' 96 , vol 58. American Society of Civil Engineers, New York

Azevedo NM, Lemos JV (2006) Hybrid discrete element/finite element method for fracture analysis. Comput Methods Appl Mech Eng 195:4579-4593. https://doi.org/10.1016/j. cma.2005.10.005

Bagavathiappan S, Lahiri BB, Saravanan T, Philip J, Jayakumar T (2013) Infrared thermography for condition monitoring-a review. Infrared Phys Technol 60:35-55. https:// doi.org/10.1016/j.infrared.2013.03.006

Bambach MR (2009) Photogrammetry measurements of buckling modes and interactions in channels with edge-stiffened flanges. Thin Walled Struct 47:485-504. https://doi.org/10. 1016/j.tws.2008.10.020

Baptista FG, Filho JV (2009) A new impedance measurement system for PZT-based structural health monitoring. IEEE Trans Instrum Meas 58:3602-3608. https://doi.org/10. 1109/TIM.2009.2018693

Bardet JP (1990) Finite-element analysis of plane-strain bifurcation within compressible solids. Comput Struct 36:993-1007. https://doi.org/10.1016/0045-7949(90)90206-h

Basarir H, Karpuz C (2016) Preliminary estimation of rock mass strength using diamond bit drilling operational parameters. Int J Min Reclam Environ 30:145-164

Basarir H, Karpuz C, Tutluoglu L (2007) A fuzzy logic based rippability classification system. J South Afr Inst Min Metall 107:817-831
Basarir H, Tutluoglu L, Karpuz C (2014) Penetration rate prediction for diamond bit drilling by adaptive neuro-fuzzy inference system and multiple regressions. Eng Geol 173:1-9

Basarir H, Wesseloo J, Karrech A, Pasternak E, Dyskin A (2017) The use of soft computing methods for the prediction of rock properties based on measurement while drilling data. In: Wesseloo J (ed) Deep mining 2017, eighth international conference on deep and high stress mining, Perth, Australia, 28-30 Mar 2017. Australian Centre for Geomechanics, pp 537-552

Bastani M, Kholghi M, Rakhshandehroo GR (2010) Inverse modeling of variable-density groundwater flow in a semiarid area in Iran using a genetic algorithm. Hydrogeol J 18:1191-1203. https://doi.org/10.1007/s10040-0100599-8

Bathe K-J (1996) Finite element procedures. Prentice-Hall, Englewood Cliffs

Beer G, Marussig B, Zechner J, Dunser C, Fries TP (2016) Isogeometric boundary element analysis with elasto-plastic inclusions. Part 1: plane problems. Comput Methods Appl Mech Eng 308:552-570. https://doi.org/10.1016/j.cma. 2016.03.035

Bellini A, Filippetti F, Tassoni C, Capolino GA (2008) Advances in diagnostic techniques for induction machines. IEEE Trans Ind Electron 55:4109-4126. https://doi.org/10. 1109/tie.2008.2007527

Bellman RA, Zadeh LA (1970) Decision making in a fuzzy environment. Manag Sci 17:141-164

Belytschko T, Lu YY, Gu L (1994) Element-free Galerkin methods. Int J Numer Methods Eng 37:229-256

Belytschko T, Krongauz Y, Organ D, Fleming M, Krysl P (1996) Meshless methods: an overview and recent developments. Comput Methods Appl Mech Eng 139:3-47

Belytschko T, Krysl P, Krongauz Y (1997) A three-dimensional explicit element-free Galerkin method. Int J Numer Meth Fluids 24:1253-1270. https://doi.org/10.1002/(sici)10970363(199706)24:12<1253::aid-fld558>3.0.co;2-z

Belytschko T, Organ D, Gerlach C (2000) Element-free Galerkin methods for dynamic fracture in concrete. Comput Methods Appl Mech Eng 187:385-399

Bogdanor MJ, Oskay C, Clay SB (2015) Multiscale modeling of failure in composites under model parameter uncertainty. Comput Mech 56:389-404. https://doi.org/10.1007/ s00466-015-1177-7

Bosse S, Lechleiter A (2016) A hybrid approach for structural monitoring with self-organizing multi-agent systems and inverse numerical methods in material-embedded sensor networks. Mechatronics 34:12-37. https://doi.org/10.1016/ j.mechatronics.2015.08.005

Brown ET, Barr MV (1978) Instrumented drilling as an aid to site investigations. In: 3rd International Congress. International Association of Engineering Geology, Madrid, pp 21-28

Broyden CG (1984) Programming the finite-element method with application to geomechanics-Smith IM. Comput J 27:94

Bruck HA, McNeill SR, Sutton MA, Peters WH (1989) Digital image correlation using Newton-Raphson method of partial differential correction. Exp Mech 29:261-267. https:// doi.org/10.1007/bf02321405 
Buechler SR, Berger JR, Mustoe GGW (2013) A discrete element approach to elastic properties of layered geomaterials. Int J Numer Anal Methods Geomech 37:685-700. https://doi.org/10.1002/nag.1115

Bunger AP, Kear J, Dyskin AV, Pasternak E (2015) Sustained acoustic emissions following tensile crack propagation in a crystalline rock. Int J Fract 193:87-98. https://doi.org/10. 1007/s 10704-015-0020-7

Cabalar AF, Cevik A, Gokceoglu C (2012) Some applications of adaptive neurofuzzy inference system (ANFIS) in geotechnical engineering. Comput Geotech 40:14-33

Cabal-Yepez E, Garcia-Ramirez AG, Romero-Troncoso RJ, Garcia-Perez A, Osornio-Rios RA (2013) Reconfigurable monitoring system for time-frequency analysis on industrial equipment through STFT and DWT. IEEE Trans Industr Inf 9:760-771. https://doi.org/10.1109/tii.2012. 2221131

Carcione JM, Poletto F (2000) Simulation of stress waves in attenuating drill strings, including piezoelectric sources and sensors. J Acoust Soc Am 108:53-64. https://doi.org/ $10.1121 / 1.429443$

Carden EP, Fanning P (2004) Vibration based condition monitoring: a review. Struct Health Monit 3:355-377. https:// doi.org/10.1177/1475921704047500

Cevik A, Sezer E, Cabalar AF, Gokceoglu C (2010) Modelling of the uniaxial compressive strength of some clay-bearing rocks using neural network. Appl Soft Comput 11:2587-2594. https://doi.org/10.1016/j.asoc.2010.10.008

Chaboche JL (1987) Continuum damage mechanics: present state and future trends. Nucl Eng Des 105:19-33. https:// doi.org/10.1016/0029-5493(87)90225-1

Chen DJ, Chiang FP, Tan YS, Don HS (1993) Digital speckledisplacement measurement using a complex spectrum method. Appl Opt 32:1839-1849. https://doi.org/10.1364/ AO.32.001839

Chen J, Zhang X, Zhan N, Hu X (2010) Deformation measurement across crack using two-step extended digital image correlation method. Opt Lasers Eng 48:1126-1131. https://doi.org/10.1016/j.optlaseng.2009.12.017

Chiaia B, Borri-Brunetto M, Carpinteri A (2013) Mathematical modelling of the mechanics of core drilling in geomaterials. Mach Sci Technol 17:1-25. https://doi.org/10.1080/ 10910344.2012.747881

Chintalapudi K et al (2006) Monitoring civil structures with a wireless sensor network. IEEE Internet Comput 10:26-34. https://doi.org/10.1109/MIC.2006.38

Chi-Young R, Chang-Sun H (2002) Development of fiber Bragg grating sensor system using wavelength-swept fiber laser. Smart Mater Struct 11:468

Chondros TG, Dimarogonas AD, Yao J (2001) Vibration of a beam with a breathing crack. J Sound Vib 239:57-67. https://doi.org/10.1006/jsvi.2000.3156

Chowdhury HA, Joldes GR, Wittek A, Doyle B, Pasternak E, Miller K (2015) Implementation of a modified moving least squares approximation for predicting soft tissue deformation using a meshless method. In: Doyle B, Miller K, Wittek A, Nielsen P (eds) Computational biomechanics for medicine. Springer, Cham. https://doi.org/10.1007/ 978-3-319-15503-6_6

Chowdhury HA, Wittek A, Miller K, Joldes GR (2017) An element free Galerkin method based on the modified moving least squares approximation. J Sci Comput 71:1197-1211

Cielo P, Maldague X, Deom AA, Lewak R (1987) Thermographic nondestructive evaluation of industrial materials and structures. Mater Eval 45:452-460

Cipolla CL, Wright CA (2000) Diagnostic techniques to understand hydraulic fracturing: what? why? and how? Paper presented at the SPE/CERI gas technology symposium, Calgary, AB, Canada, 3-5 Apr 2000

Clearly PW, Prakash M (2004) Discrete-element modelling and smoothed particle hydrodynamics: potential in the environmental sciences. Philos Trans R Soc Lond Ser A Math Phys Eng Sci 362:2003

Crouch RD, Clay SB, Oskay C (2013) Experimental and computational investigation of progressive damage accumulation in CFRP composites. Compos B Eng 48:59-67. https:// doi.org/10.1016/j.compositesb.2012.12.005

Cundall PA, Strack OD (1979) A discrete numerical model for granular assemblies. Geotechnique 29:47-65

Dagdelenler G, Sezer E, Gokceoglu C (2011) Some non-linear models to predict the weathering degrees of a granitic rock from physical and mechanical parameters. Expert Syst Appl 38:7476-7485

De Azevedo HDM, Araújo AM, Bouchonneau N (2016) A review of wind turbine bearing condition monitoring: state of the art and challenges. Renew Sustain Energy Rev 56:368-379. https://doi.org/10.1016/j.rser.2015.11.032

Debella-Gilo M, Kääb A (2011) Sub-pixel precision image matching for measuring surface displacements on mass movements using normalized cross-correlation. Remote Sens Environ 115:130-142

Deketh H, Alvarez Grima M, Hergarden I, Giezen M, Verhoef P (1998) Towards the prediction of rock excavation machine performance. Bull Eng Geol Environ 57:3-15

den Hartog MH, Babuška R, Deketh HJR, Alvarez Grima M, Verhoef PNW, Verbruggen HB (1997) Fuzzy logic applications: knowledge-based fuzzy model for performance prediction of a rock-cutting trencher. Int J Approx Reason 16:43-66. https://doi.org/10.1016/S0888-613X (96)00118-1

Deraemaeker A, Worden K (eds) (2010) New trends in vibration based structural health monitoring. CISM courses and lectures, vol 520. Springer, Wien

Detournay E, Richard T, Shepherd M (2008) Drilling response of drag bits: theory and experiment. Int J Rock Mech Min Sci 45:1347-1360. https://doi.org/10.1016/j.ijrmms.2008. 01.010

Deveaux MR, Alessandrello E, Lemoine Y (1983) Instantaneous logging in water survey. Bull Int Assoc Eng Geol 26-27:59-63

Di Sante R (2015) Fibre optic sensors for structural health monitoring of aircraft composite structures: recent advances and applications. Sensors (Switzerland) 15:18666-18713. https://doi.org/10.3390/s150818666

Dietrich CR, Newsam GN (1990) Sufficient conditions for identifying transmissivity in a confined aquifer. Inverse Prob 6:L21

Dimarogonas A (1996) Vibration of cracked structures: a state of the art review. Eng Fract Mech 55:831-857

Doebling SW, Farrar CR, Prime MB, Shevitz DW (1996) Damage identification and health monitoring of structural 
and mechanical systems from changes in their vibration characteristics: a literature review. Los Alamos National Lab, Los Alamos

Doebling SW, Farrar CR, Prime MB (1998) A summary review of vibration-based damage identification methods. Shock Vib Dig 30:91-105

Drumheller DS (1989) Acoustical properties of drill strings. J Acoust Soc Am 85:1048-1064. https://doi.org/10.1121/1. 397488

Dyskin AV (2002) Self-similar crack patterns induced by spatial stress fluctuations. Fatigue Fract Eng Mater Struct 25:187-200. https://doi.org/10.1046/j.8756-758x.2002. 00487.x

Dyskin AV (2004) Continuum fractal mechanics of the Earth's crust. Pure appl Geophys 161:1979-1989. https://doi.org/ 10.1007/s00024-004-2544-2

Dyskin AV (2005) Effective characteristics and stress concentrations in materials with self-similar microstructure. Int $\mathrm{J}$ Solids Struct 42:477-502. https://doi.org/10.1016/j. ijsolstr.2004.06.034

Dyskin AV (2006) Multifractal properties of self-similar stress distributions. Philos Mag 86:3117-3136. https://doi.org/ 10.1080/14786430500421490

Dyskin AV (2007) Self-similar pattern formation and continuous mechanics of self-similar systems. Hydrol Earth Syst Sci 11:665-676. https://doi.org/10.5194/hess-11-665-2007

Dyskin AV (2008) Parallel Fault Systems with Evolving Selfsimilar Sliding Zones. Pure appl Geophys 165:545-565. https://doi.org/10.1007/s00024-008-0323-y

Dyskin AV, Pasternak E, Sevel G, Cardell-Oliver R (2011) Smart proppant concept for monitoring hydraulic fractures. APPEA J 51:527-533

Dyskin AV, Pasternak E, Pelinovsky E (2012) Periodic motions and resonances of impact oscillators. J Sound Vib 331:2856-2873. https://doi.org/10.1016/j.jsv.2012.01.031

Dyskin AV, Pasternak E, Shufrin I (2013) Vertical vibrations in rotary drilling systems. Aust J Multi Discipl Eng. https:// doi.org/10.7158/n13-ac09.2013.10.2

Dyskin AV, Pasternak E, Shufrin I (2014) Structure of resonances and formation of stationary points in symmetrical chains of bilinear oscillators. J Sound Vib 333:6590-6606. https://doi.org/10.1016/j.jsv.2014.06.044

Dysli M (1983) Use of ADINA in soil mechanics with case studies for excavations. Comput Struct 17:635-642. https://doi.org/10.1016/0045-7949(83)90075-5

El-Thalji I, Jantunen E (2015) A summary of fault modelling and predictive health monitoring of rolling element bearings. Mech Syst Signal Process 60:252-272. https://doi. org/10.1016/j.ymssp.2015.02.008

Esin M, Dyskin AV, Pasternak E, Xu Y (2017) Mode I crack in particulate materials with rotational degrees of freedom. Eng Fract Mech 172:181-195. https://doi.org/10.1016/j. engfracmech.2016.12.024

Fagerholt E, Børvik T, Hopperstad OS (2013) Measuring discontinuous displacement fields in cracked specimens using digital image correlation with mesh adaptation and crackpath optimization. Opt Lasers Eng 51:299-310. https://doi. org/10.1016/j.optlaseng.2012.09.010

Fajklewicz Z (1996) Microgravity stochastic prediction for mine tremors and dynamic processes in the rockmass. Publ Inst Geophys 18:126
Fakhimi A, Lanari M (2014) DEM-SPH simulation of rock blasting. Comput Geotech 55:158-164. https://doi.org/10. 1016/j.compgeo.2013.08.008

Fan W, Qiao P (2011) Vibration-based damage identification methods: a review and comparative study. Struct Health Monit 10:83-111. https://doi.org/10.1177/ 1475921710365419

Farrar CR, Worden K (2012) Structural health monitoring: a machine learning perspective. Wiley, London

Farreras-Alcover I, Chryssanthopoulos MK, Andersen JE (2017) Data-based models for fatigue reliability of orthotropic steel bridge decks based on temperature, traffic and strain monitoring. Int J Fatigue 95:104-119. https://doi. org/10.1016/j.ijfatigue.2016.09.019

Fattahi H (2016) Indirect estimation of deformation modulus of an in situ rock mass: an ANFIS model based on grid partitioning, fuzzy c-means clustering and subtractive clustering. Geosci J 20:681-690. https://doi.org/10.1007/ s12303-015-0065-7

Fernandes H, Ibarra-Castanedo C, Zhang H, Maldague X (2015) Thermographic non-destructive evaluation of carbon fiberreinforced polymer plates after tensile testing. J Nondestr Eval 34:35. https://doi.org/10.1007/s10921-015-0303-y

Finger JT, Mansure AJ, Knudsen SD, Jacobson RD (2003) Development of a system for diagnostic-while-drilling (DWD). Paper presented at the SPE/IADC drilling conference, Amsterdam, The Netherlands, 19-21 Feb 2003

Finol J, Guo Y, Jing X (2001) A rule based fuzzy model for the prediction of petrophysical rock parameters. J Pet Sci Eng 29:97-113

Franke S, Franke B, Rautenstrauch K (2006) Strain analysis of wood components by close range photogrammetry. Mater Struct 40:37-46. https://doi.org/10.1617/s11527-006-9152-6

Fraser CS (1992) Photogrammetric measurement to one part in a million. Photogramm Eng Remote Sens 58:305-310

Fraser CS, Cronk S (2009) A hybrid measurement approach for close-range photogrammetry. ISPRS J Photogramm Remote Sens 64:328-333. https://doi.org/10.1016/j. isprsjprs.2008.09.009

Fraser CS, Riedel B (2000) Monitoring the thermal deformation of steel beams via vision metrology. ISPRS J Photogramm Remote Sens 50:268-276

Fraser CS, Woods A, Brizzi D (2005) Hyper redundancy for accuracy enhancement in automated close range photogrammetry. Photogramm Rec 20:205-217

Friswell M, Penny J (1992) A simple nonlinear modal of a cracked beam. 10th international modal analysis conference. San Diego, California, pp 516-521

Gade SO, Weiss U, Peter MA, Sause MGR (2014) Relation of electromagnetic emission and crack dynamics in epoxy resin materials. J Nondestr Eval 33:711-723. https://doi. org/10.1007/s10921-014-0265-5

Gandelman RA et al (2013) Real time drilling data diagnosis implemented in deepwater wells - a reality. Paper presented at the Offshore Technology Conference, Rio de Janeiro, Brasil, 29-31 Oct 2013

Gao Z, Cecati C, Ding SX (2015a) A survey of fault diagnosis and fault-tolerant techniques-part II: fault diagnosis with knowledge-based and hybrid/active approaches. IEEE Trans Ind Electron 62:3768-3774. https://doi.org/10.1109/ tie.2015.2419013 
Gao Z, Cecati C, Ding SX (2015b) A survey of fault diagnosis and fault-tolerant techniques, part I: fault diagnosis with model-based and signal-based approaches. IEEE Trans Ind Electron 62:3757-3767. https://doi.org/10.1109/tie.2015. 2417501

Garcia LA, Shigidi A (2006) Using neural networks for parameter estimation in ground water. J Hydrol 318:215-231. https://doi.org/10.1016/j.jhydrol.2005.05. 028

Garrett J (1994) Where and why artificial neural networks are applicable in civil engineering. J Comput Civ Eng 8:129-130

Georgescu S, Chow P, Okuda H (2013) GPU acceleration for FEM-based structural analysis. Arch Comput Methods Eng 20:111-121. https://doi.org/10.1007/s11831-013-9082-8

Gingold RA, Monaghan JJ (1977) Smoothed particle hydrodynamics: theory and application to non-spherical stars. Mon Not R Astr Soc 181:375-389

Giniotis V, Hope A (2014) Measurement and monitoring. Automation and control and mechanical engineering collection. Momentum Press, New York

Gokay MK (1998) Fuzzy logic usage in rock mass classifications. J Cham Min Eng Turkey 37:3-11

Gokceoglu C, Yesilnacar E, Sonmez H, Kayabasi A (2004) A neuro-fuzzy model for the deformation modulus of jointed rock masses. Comput Geotech 31:375-383

Goyal D, Pabla BS (2015) Condition based maintenance of machine tools - a review. CIRP J Manufact Sci Technol 10:24-35. https://doi.org/10.1016/j.cirpj.2015.05.004

Grima AM, Babuska R (1999) Fuzzy model for the prediction of unconfined compressive strength of rock samples. Int J Rock Mech Min Sci 36:339-349

Grinzato E, Bison PG, Marinetti S (2002) Monitoring of ancient buildings by the thermal method. J Cult Herit 3:21-29. https://doi.org/10.1016/S1296-2074(02)01159-7

Grosse C, Ohtsu M (2008) Acoustic emission testing [electronic resource]: basics for research-applications in civil engineering. Springer, Berlin

Guan X, Liu X, Jia X, Yuan Y, Cui J, Mang HA (2015) A stochastic multiscale model for predicting mechanical properties of fiber reinforced concrete. Int J Solids Struct 56-57:280-289. https://doi.org/10.1016/j.ijsolstr.2014.10. 008

Guzek A, Shufrin I, Pasternak E, Dyskin AV (2015) Influence of drilling mud rheology on the reduction of vertical vibrations in deep rotary drilling. J Pet Sci Eng 135:375-383. https://doi.org/10.1016/j.petrol.2015.09.016

Ha H-G, Jang I-S, Ko K-W, Ha Y-H (2009) Robust subpixel shift estimation using iterative phase correlation of a local region. In: IS\&T/SPIE electronic imaging. SPIE, p 9

Habibagahi G, Katebi S (1996) Rock mass classification using fuzzy sets. Iran J Sci Technol 20:273-284

Haeri MH, Lotfi A, Dolatshahi KM, Golafshani AA (2017) Inverse vibration technique for structural health monitoring of offshore jacket platforms. Appl Ocean Res 62:181-198. https://doi.org/10.1016/j.apor.2016.11.010

Hallquist JO (2005) LS-DYNA theory manual. Livermore Software Technology Corporation, Livermore

Hameed Z, Hong YS, Cho YM, Ahn SH, Song CK (2009) Condition monitoring and fault detection of wind turbines and related algorithms: a review. Renew Sustain Energy Rev 13:1-39. https://doi.org/10.1016/j.rser.2007.05.008

Hassan GM, MacNish C, Dyskin A (2015) Extending digital image correlation to reconstruct displacement and strain fields around discontinuities in geomechanical structures under deformation. In: 2015 IEEE winter conference on applications of computer vision, pp 710-717, 5-9 Jan 2015. https://doi.org/10.1109/wacv.2015.100

Hassan GM, Dyskin AV, MacNish CK, Pasternak E, Shufrin I (2017) Discontinuous digital image correlation to reconstruct displacement and strain fields with discontinuities: dislocation approach. Eng Fract Mech. https://doi.org/10. 1016/j.engfracmech.2017.11.022

Hatherly P, Leung R, Scheding S, Robinson D (2015) Drill monitoring results reveal geological conditions in blast hole drilling. Int J Rock Mech Min Sci 78:144-154

Helm J (2008) Digital image correlation for specimens with multiple growing cracks. Exp Mech 48:753-762

Heng A, Zhang S, Tan ACC, Mathew J (2009) Rotating machinery prognostics: state of the art, challenges and opportunities. Mech Syst Signal Process 23:724-739. https://doi.org/10.1016/j.ymssp.2008.06.009

Heo Y, Zavala VM (2012) Gaussian process modeling for measurement and verification of building energy savings. Energy Build 53:7-18. https://doi.org/10.1016/j.enbuild. 2012.06.024

Holford KM, Eaton MJ, Hensman JJ, Pullin R, Evans SL, Dervilis N, Worden K (2017) A new methodology for automating acoustic emission detection of metallic fatigue fractures in highly demanding aerospace environments: an overview. Prog Aerosp Sci 90:1-11. https://doi.org/10. 1016/j.paerosci.2016.11.003

Horton A, Wittek A, Joldes GR, Miller K (2010) A meshless Total Lagrangian explicit dynamics algorithm for surgical simulation. Int J Numer Methods Biomed Eng 26:977-998. https://doi.org/10.1002/cnm.1374

Hughes TJR, Cottrell JA, Bazilevs Y (2005) Isogeometric analysis: CAD, finite elements, NURBS, exact geometry and mesh refinement. Comput Methods Appl Mech Eng 194:4135-4195. https://doi.org/10.1016/j.cma.2004.10. 008

Hunt TM (2006) The concise encyclopaedia of condition monitoring: including a guide to 15 condition monitoring techniques. Coxmoor Publishing Company, Longborough

Huston D (2010) Structural sensing, health monitoring, and performance evaluation. CRC Press, Hoboken

Huthwaite P (2014) Accelerated finite element elastodynamic simulations using the GPU. J Comput Phys Part A 257:687-707. https://doi.org/10.1016/j.jcp.2013.10.017

Inagaki T, Okamoto Y (1997) Diagnosis of the leakage point on a structure surface using infrared thermography in near ambient conditions. NDT E Int 30:135-142. https://doi. org/10.1016/S0963-8695(96)00040-0

Iphar M, Yavuz M, Ak H (2008) Prediction of ground vibrations resulting from the blasting operations in an open-pit mine by adaptive neuro-fuzzy inference system. Environ Geol 56:97-107

Isermann R (2005) Model-based fault-detection and diagnosis-Status and applications. Annu Rev Control 29:71-85. https://doi.org/10.1016/j.arcontrol.2004.12.002 
Jardine AKS, Lin D, Banjevic D (2006) A review on machinery diagnostics and prognostics implementing condition-based maintenance. Mech Syst Signal Process 20:1483-1510. https://doi.org/10.1016/j.ymssp.2005.09.012

Jenson D, Unnikrishnan VU (2015) Energy dissipation of nanocomposite based helmets for blast-induced traumatic brain injury mitigation. Compos Struct 121:211-216. https://doi.org/10.1016/j.compstruct.2014.08.028

Jessica M-S (2005) Wireless sensor networks: an information processing approach. Sens Rev. https://doi.org/10.1108/sr. 2005.08725bae.001

Jhang KY (2009) Nonlinear ultrasonic techniques for non-destructive assessment of micro damage in material: a review. Int J Precis Eng Manuf 10:123-135. https://doi. org/10.1007/s12541-009-0019-y

Jiang R, Jáuregui DV, White KR (2008) Close-range photogrammetry applications in bridge measurement: literature review. Measurement 41:823-834. https://doi.org/10. 1016/j.measurement.2007.12.005

Jin X, Joldes GR, Miller K, Yang KH, Wittek A (2014) Meshless algorithm for soft tissue cutting in surgical simulation. Comput Methods Biomech Biomed Eng 17:800-817. https://doi.org/10.1080/10255842.2012.716829

Jing LH, Duan SC, Yang SQ (2007) Application of seepage back analysis to engineering design. Chin J Rock Mech Eng 26:4503-4509

Joldes GR, Wittek A, Miller K (2010) Real-time nonlinear finite element computations on GPU-application to neurosurgical simulation. Comput Methods Appl Mech Eng 199:3305-3314

Joldes GR, Wittek A, Miller K (2011) An adaptive dynamic relaxation method for solving nonlinear finite element problems. Application to brain shift estimation. Int $\mathbf{J}$ Numer Methods Biomed Eng 27:173-185

Joldes GR, Chowdhury AH, Wittek A, Doyle B, Miller K (2015a) Modified moving least squares with polynomial bases for scattered data approximation. Appl Math Comput. https://doi.org/10.1016/j.amc.2015.05.150

Joldes GR, Wittek A, Miller K (2015b) Adaptive numerical integration in element-free Galerkin methods for elliptic boundary value problems. Eng Anal Bound Elem 51:52-63. https://doi.org/10.1016/j.enganabound.2014.10. 007

Joldes GR, Wittek A, Miller K (2015c) Adaptive numerical integration in element-free Galerkin methods for elliptic boundary value problems. Eng Anal Bound Elem. https:// doi.org/10.1016/j.enganabound.2014.10.007

Joldes GR, Chowdhury AH, Wittek A, Miller K (2017) A new method for essential boundary conditions imposition in explicit meshless methods. Eng Anal Bound Elem 80:94-104

Juang CH, Lee DH (1990) Rock mass classification using fuzzy sets. Paper presented at the proceedings of the tenth Southeast Asian geotechnical conference, Taipei, ROC

Kachanov LM (1958) Time of rupture process under creep conditions. Izv Akad Nauk USSR 8:26-30

Kahraman S, Rostami J, Naeimipour A (2015) Review of ground characterization by using instrumented drills for underground mining and construction. Rock Mech Rock Eng 49:585-602. https://doi.org/10.1007/s00603-0150756-4
Kardani M, Nazem M, Sheng D, Carter JP (2013) Large deformation analysis of geomechanics problems by a combined rh-adaptive finite element method. Comput Geotech 49:90-99. https://doi.org/10.1016/j.compgeo. 2012.09.013

Kardani O, Lyamin A, Krabbenhøft K (2015) Application of a GPU-accelerated hybrid preconditioned conjugate gradient approach for large 3D problems in computational geomechanics. Comput Math Appl 69:1114-1131. https://doi. org/10.1016/j.camwa.2015.03.003

Karrech A et al (2007) A computational procedure for the prediction of settlement in granular materials under cyclic loading. Comput Methods Appl Mech Eng 197:80-94. https://doi.org/10.1016/j.cma.2007.07.011

Karrech A, Duhamel D, Bonnet G, Chevoir F, Roux J-N, Canou J, Dupla J-C (2008) A discrete element study of settlement in vibrated granular layers: role of contact loss and acceleration. Granul Matter 10:369. https://doi.org/10.1007/ s10035-008-0101-7

Karrech A, Regenauer-Lieb K, Poulet T (2011a) Continuum damage mechanics for the lithosphere. J Geophys Res Solid Earth. https://doi.org/10.1029/2010jb007501

Karrech A, Regenauer-Lieb K, Poulet T (2011b) A damaged visco-plasticity model for pressure and temperature sensitive geomaterials. Int J Eng Sci 49:1141-1150. https://doi. org/10.1016/j.ijengsci.2011.05.005

Karrech A, Schrank C, Freij-Ayoub R, Regenauer-Lieb K (2014) A multi-scaling approach to predict hydraulic damage of poromaterials. Int J Mech Sci 78:1-7. https:// doi.org/10.1016/j.ijmecsci.2013.10.010

Karrech A, Abbassi F, Basarir H, Attar M (2017) Self-consistent fractal damage of natural geo-materials in finite strain. Mech Mater 104:107-120. https://doi.org/10.1016/j. mechmat.2016.08.017

Kayabasi A, Gokceoglu C, Ercanoglu M (2003) Estimating the deformation modulus of rock masses: a comparative study. Int J Rock Mech Min Sci 40:55-63

Khandelwal M, Ranjith PG (2010) Correlating index properties of rocks with P-wave measurements. J Appl Geophys 71:1-5. https://doi.org/10.1016/j.jappgeo.2010.01.007

Kim BS, Roh YR (2008) Piezoelectric sensor system for structural health monitoring. Adv Sci Technol 56:194-199

Kim YR, Souza FV, Park T (2013) Multiscale modeling of damage evolution in viscoelastic bituminous mixtures subjected to cyclic loading. J Eng Mater Technol Trans ASME. https://doi.org/10.1115/1.4023773

King GE (2011) Tracking fracture fluid movement with chemical and gamma-emitting tracers with verification by microseismic recording. Paper presented at the EPA hydraulic fracturing workshop, Arlington, VA, USA, 24-25 Feb 2011

Koh CG, Chen YF, Liaw CY (2003) A hybrid computational strategy for identification of structural parameters. Comput Struct 81:107-117. https://doi.org/10.1016/s00457949(02)00344-9

Komoroczi A, Abe S, Urai JL (2013) Meshless numerical modeling of brittle-viscous deformation: first results on boudinage and hydrofracturing using a coupling of discrete element method (DEM) and smoothed particle hydrodynamics (SPH). Comput Geosci 17:373-390. https://doi. org/10.1007/s10596-012-9335-X 
Kordatos EZ, Aggelis DG, Matikas TE (2012) Monitoring mechanical damage in structural materials using complimentary NDE techniques based on thermography and acoustic emission. Compos B Eng 43:2676-2686. https:// doi.org/10.1016/j.compositesb.2011.12.013

Kozin F, Natke HG (1986) System identification techniques. Struct Saf 3:269-316. https://doi.org/10.1016/01674730(86)90006-8

Krongauz Y, Belytschko T (1996) Enforcement of essential boundary conditions in meshless approximations using finite elements. Comput Methods Appl Mech Eng 131:133-145

Kruggel-Emden H, Simsek E, Rickelt S, Wirtz S, Scherer V (2007) Review and extension of normal force models for the Discrete Element Method. Powder Technol 171:157-173. https://doi.org/10.1016/j.powtec.2006.10.004

Kucuk K, Aksoy C, Basarir H, Onargan T, Genis M, Ozacar M (2011) Prediction of the performance of impact hammer by adaptive neuro-fuzzy inference system modeling. Tunneling Underground Space Technol 26

Kurita K, Oyado M, Tanaka H, Tottori S (2009) Active infrared thermographic inspection technique for elevated concrete structures using remote heating system. Infrared Phys Technol 52:208-213. https://doi.org/10.1016/j.infrared. 2009.07.010

Kusiak A, Zhang Z, Verma A (2013) Prediction, operations, and condition monitoring in wind energy. Energy 60:1-12. https://doi.org/10.1016/j.energy.2013.07.051

Laouti N, Othman S, Alamir M, Sheibat-Othman N (2015) Combination of model-based observer and support vector machines for fault detection of wind turbines. Int J Autom Comput 11:274-287. https://doi.org/10.1007/s11633-0140790-9

Lee TK, Al-Mahaidi R (2008) An experimental investigation on shear behaviour of RC T-beams strengthened with CFRP using photogrammetry. Compos Struct 82:185-193. https://doi.org/10.1016/j.compstruct.2006.12.012

Lee H, Jeon S, Kim J (2003) Development of a fuzzy model to estimate engineering rock mass properties. In: Proceedings of the 10th Congress of the ISRM-technology roadmap for rock mechanics, Sandton City, South Africa, pp 749-752

Lei Y, Lin J, Zuo MJ, He Z (2014) Condition monitoring and fault diagnosis of planetary gearboxes: a review. Measurement 48:292-305. https://doi.org/10.1016/j.measurement.2013. 11.012

Lemaitre J (1985) Coupled elasto-plasticity and damage constitutive equations. Comput Methods Appl Mech Eng 51:31-49. https://doi.org/10.1016/0045-7825(85)90026-X

Lemaitre J, Chaboche J (2001) Mécanique des matériaux solides. Duond, Paris

Levy R, Arogeti SA, Wang D (2014) An integrated approach to mode tracking and diagnosis of hybrid systems. IEEE Trans Ind Electron 61:2024-2040. https://doi.org/10.1109/ tie.2013.2262761

Lewis AW, Yuen STS, Smith AJR (2003) Detection of gas leakage from landfills using infrared thermography-applicability and limitations. Waste Manag Res 21:436-447. https://doi.org/10.1177/0734242x0302100506
Li X (2002) A brief review: acoustic emission method for tool wear monitoring during turning. Int $\mathrm{J}$ Mach Tools Manuf 42:157-165. https://doi.org/10.1016/s0890-6955(01)00108-0

Li Z, Jiang Y, Hu C, Peng Z (2016) Recent progress on decoupling diagnosis of hybrid failures in gear transmission systems using vibration sensor signal: a review. Measurement 90:4-19. https://doi.org/10.1016/j. measurement.2016.04.036

Lu H, Cary PD (2000) Deformation measurements by digital image correlation: implementation of a second-order displacement gradient. Exp Mech 40:393-400. https://doi. org/10.1007/bf02326485

Lu G, Third JR, Müller CR (2015) Discrete element models for non-spherical particle systems: from theoretical developments to applications. Chem Eng Sci 127:425-465

Luan M, Yang X, Tian R, Yang Q (2005) Numerical analysis on progressive fracture behavior by using element-free method based on finite covers. Int $\mathrm{J}$ Comput Methods 02:543-553. https://doi.org/10.1142/S0219876205000600

Lucy LB (1977) A numerical approach to the testing of the fission hypothesis. Astron J 82:1013-1024

Luhmann T (2006) Close range photogrammetry: principles, methods and applications. Whittles, Dunbeath

Luhmann T (2010) Close range photogrammetry for industrial applications. ISPRS J Photogramm Remote Sens 65:558-569. https://doi.org/10.1016/j.isprsjprs.2010.06.003

Lüthi T, Meier H, Primas R, Zogmal O (1995) Infrared inspection of external bonded CFPR-Sheets. In: International symposium non-destructive testing in civil engineering (NDT-CE), Berlin, Germany, pp 689-704

Lyakhovsky V, Hamiel Y, Ampuero JP, Ben-Zion Y (2009) Non-linear damage rheology and wave resonance in rocks. Geophys J Int 178:910-920. https://doi.org/10.1111/j. 1365-246X.2009.04205.x

Lynch JP (2006) A summary review of wireless sensors and sensor networks for structural health monitoring. Shock Vib Dig 38:91-128. https://doi.org/10.1177/ 0583102406061499

Ma S, Guanchang J (2003) Digital speckle correlation method improved by genetic algorithm. Acta Mech Solida Sin 16:366-373

Ma T, Chen P, Han X (2015) Simulation and interpretation of the pressure response for formation testing while drilling. J Nat Gas Sci Eng 23:259-271. https://doi.org/10.1016/j. jngse.2015.01.044

Maalej M, Karasaridis A, Pantazopoulou S, Hatzinakos D (2002) Struct Health Monit Smart Struct. Smart Mater Struct 11:581

MacNish C, Hassan GM, Dyskin AV, Pasternak E (2015) Towards affordable and robust remote photogrammetric sensing for early warning of fracturing and structural failure. In: 2015 IEEE Region 10 humanitarian technology conference (R10-HTC), 9-12 Dec 2015, pp 1-6. https:// doi.org/10.1109/r10-htc.2015.7391869

Macpherson JD, Jogi PN, Kingman JEE (2001) Application and analysis of simultaneous near bit and surface dynamics measurements. SPE Drill Complet 16:230-238

Mahrer KD (1999) A review and perspective on far-field hydraulic fracture geometry studies. J Pet Sci Eng 24:13-28. https:// doi.org/10.1016/S0920-4105(99)00020-0 
Marigo M, Stitt EH (2015) Discrete element method (DEM) for industrial applications: comments on calibration and validation for the modelling of cylindrical pellets. KONA Powder Part J 32:236-252

Martin HC, Carey GF (1973) Introduction to finite element analysis: theory and application. McGraw-Hill Book, New York

Marwala T (2012) Condition monitoring using computational intelligence methods. Springer, London

Marzat J, Piet-Lahanier H, Damongeot F, Walter E (2012) Modelbased fault diagnosis for aerospace systems: a survey. Proc Inst Mech Eng Part G J Aerosp Eng 226:1329-1360. https:// doi.org/10.1177/0954410011421717

Mendioroz A, Celorrio A, Salazar A (2017) Ultrasound excited thermography: an efficient tool for the characterization of vertical cracks. Meas Sci Technol 28:112001

Monaghan JJ (1992) Smoothed particle hydrodynamics. Ann Rev Astron Astrophys 30:543-574

Montalvo D, Maia N, Ribeiro A (2006) A review of vibrationbased structural health monitoring with special emphasis on composite materials. Shock Vib Dig 38:1-30

Moresi L, Dufour F, Mühlhaus HB (2003) A Lagrangian integration point finite element method for large deformation modeling of viscoelastic geomaterials. J Comput Phys 184:476-497. https://doi.org/10.1016/S0021-9991(02)00031-1

Mori Y, Obata Y, Sikula J (2009) Acoustic and electromagnetic emission from crack created in rock sample under deformation. J Acoust Emiss 27:157-166

Müftüoglu YV (1983) A study of factors affecting diggability in British surface coal mines. Ph.D. thesis, University of Nottingham, England

Murakami A, Setsuyasu T, Arimoto S-I (2005) Mesh-free method for soil-water coupled problem within finite strain and its numerical validity. Soils Found 45:145-154. https:// doi.org/10.3208/sandf.45.2_145

Muralidhar C, Arya NK (1993) Evaluation of defects in axisymmetric composite structures by thermography. NDT E Int 26:189-193. https://doi.org/10.1016/09638695(93)90473-8

Naidu A, Bhalla S, Soh CK (2002) Incipient damage localization with smart piezoelectric transducers using high-frequency actuation. In: SPIE international symposium on smart materials, nano-, and micro-smart systems, Melbourne, Australia, 16-18 Dec 2002

Nandi S, Toliyat HA, Li X (2005) Condition monitoring and fault diagnosis of electrical motors - a review. IEEE Trans Energy Convers 20:719-729. https://doi.org/10.1109/tec. 2005.847955

Nguyen VU (1985) Some fuzzy set applications in mining geomechanics. Int J Rock Mech Min Sci Geomech Abstr 22:369-379

Nguyen VU, Ashworth EA (1985) Rock mass classification by fuzzy sets. Paper presented at the 26th US symposium on rock mechanics, Rapid City, SD

Nguyen TL, Hall SA, Vacher P, Viggiani G (2011) Fracture mechanisms in soft rock: identification and quantification of evolving displacement discontinuities by extended digital image correlation. Tectonophysics 503:117-128

Nguyen MN, Bui TQ, Yu TT, Hirose S (2014) Isogeometric analysis for unsaturated flow problems. Comput Geotech
62:257-267. https://doi.org/10.1016/j.compgeo.2014.08. 003

Noorsuhada MN (2016) An overview on fatigue damage assessment of reinforced concrete structures with the aid of acoustic emission technique. Constr Build Mater 112:424-439. https://doi.org/10.1016/j.conbuildmat.2016. 02.206

Onate E, Rojek J (2004) Combination of discrete element and finite element methods for dynamic analysis of geomechanics problems. Comput Methods Appl Mech Eng 193:3087-3128. https://doi.org/10.1016/j.cma.2003.12. 056

Pan B, Li K (2011) A fast digital image correlation method for deformation measurement. Opt Lasers Eng 49:841-847. https://doi.org/10.1016/j.optlaseng.2011.02.023

Park G, Sohn H, Farrar CR, Inman DJ (2003) Overview of piezoelectric impedance-based health monitoring and path forward. Shock Vib Dig 35:451-463

Park G, Farrar CR, Rutherford AC, Robertson AN (2006) Piezoelectric active sensor self-diagnostics using electrical admittance measurements. J Vib Acoust 128:469-476. https://doi.org/10.1115/1.2202157

Parkinson G, Ékes C (2008) Ground penetrating radar evaluation of concrete tunnel linings. Paper presented at the 12th international conference on ground penetrating radar, Birmingham, UK, 16-19 June 2008

Pasternak E, Dyskin AV, Esin M, Hassan GM, MacNish C (2015) Rotations and pattern formation in granular materials under loading. Philos Mag 95:3122-3145. https://doi. org/10.1080/14786435.2015.1059517

Pastor M, Haddad B, Sorbino G, Cuomo S, Drempetic V (2009) A depth-integrated, coupled SPH model for flow-like landslides and related phenomena. Int $\mathrm{J}$ Numer Anal Methods Geomech 33:143-172. https://doi.org/10.1002/ nag.705

Pastor M, Chan AHC, Mira P, Manzanal D, Merodo JAF, Blanc $\mathrm{T}$ (2011) Computational geomechanics: the heritage of Olek Zienkiewicz. Int J Numer Methods Eng 87:457-489. https://doi.org/10.1002/nme.3192

Peck R (1969) Advantages and limitations of the observational method in applied soil mechanics. Geotechnique 19:171-187

Peng ZK, Lang ZQ, Chu FL (2008) Numerical analysis of cracked beams using nonlinear output frequency response functions. Comput Struct 86:1809-1818. https://doi.org/ 10.1016/j.compstruc.2008.01.011

Peng Y, Dong M, Zuo MJ (2010) Current status of machine prognostics in condition-based maintenance: a review. Int $\mathrm{J}$ Adv Manuf Technol 50:297-313. https://doi.org/10.1007/ s00170-009-2482-0

Peters W, Ranson W, Sutton M, Chu T, Anderson J (1983) Application of digital correlation methods to rigid body mechanics. Opt Eng 22:738-742

Phillips J, Cripps E, Lau JW, Hodkiewicz MR (2015) Classifying machinery condition using oil samples and binary logistic regression. Mech Syst Signal Process 60-61:316-325. https://doi.org/10.1016/j.ymssp.2014.12. 020

Pilch A, Mahajan A, Chu T (2004) Measurement of whole-field surface displacements and strain using a genetic algorithm 
based intelligent image correlation method. J Dyn Syst Meas Control 126:479

Pitter M, See CW, Somekh M (2001) Subpixel microscopic deformation analysis using correlation and artificial neural networks. Opt Express 8:322-327

Pixton DS, Asgharzadeh Shishavan R, Perez HD, Hedengren JD, Craig A (2014) Addressing UBO and MPD challenges with wired drill pipe telemetry. Paper presented at the SPE/ IADC managed pressure drilling and underbalanced operations conference and exhibition, Madrid, Spain, 8-9 Apr 2014

Poissant J, Barthelat F (2010) A novel subset splitting procedure for digital image correlation on discontinuous displacement fields. Exp Mech 50:353-364

Poletto F, Miranda F (2004) Seismic while drilling-fundamentals of drill-bit seismic for exploration. Seismic exploration, vol 35. Elsevier, Amsterdam

Pramanik R, Deb D (2015) SPH procedures for modeling multiple intersecting discontinuities in geomaterial. Int $\mathbf{J}$ Numer Anal Methods Geomech 39:343-367. https://doi. org/10.1002/nag.2311

Prime MB, Shevitz DW (1996) Linear and nonlinear methods for detecting cracks in beams. In: 14th international modal analysis conference, Dearborn, Michigan, USA, pp 1437-1443

Priya S, Inman DJ (2008) Energy harvesting technologies. Springer, New York

Qi X, Lichti DD, El-Badry M, Chan TO, El-Halawany SI, Lahamy H, Steward J (2014) Structural dynamic deflection measurement with range cameras. Photogramm Rec 29:89-107. https://doi.org/10.1111/phor.12047

Rabotnov YN (1969) Creep problems in structural members. North-Holland, Amsterdam

Raju V (1997) Implementing impedance-based health monitoring. Virginia Tech, Blacksburg

Rechenmacher A, Abedi S, Chupin O, Orlando A (2011) Characterization of mesoscale instabilities in localized granular shear using digital image correlation. Acta Geotech 6:205-217

Rehorn AG, Jiang J, Orban PE (2005) State-of-the-art methods and results in tool condition monitoring: a review. Int J Adv Manuf Technol 26:693-710. https://doi.org/10.1007/ s00170-004-2038-2

Rivola A, White PR (1998) Bispectral analysis of the bilinear oscillator with application to the detection of fatigue cracks. J Sound Vib 216:889-910. https://doi.org/10.1006/ jsvi.1998.1738

Rodriguez-Paz M, Bonet J (2005) A corrected smooth particle hydrodynamics formulation of the shallow-water equations. Comput Struct 83:1396-1410. https://doi.org/10. 1016/j.compstruc.2004.11.025

Romhány G, Czigány T, Karger-Kocsis J (2017) Failure assessment and evaluation of damage development and crack growth in polymer composites via localization of acoustic emission events: a review. Polym Rev 57:397-439. https:// doi.org/10.1080/15583724.2017.1309663

Roux S, Hild F (2006) Stress intensity factor measurements from digital image correlation: post-processing and integrated approaches. Int J Fract 140:141-157. https://doi.org/ 10.1007/s10704-006-6631-2
Roux S, Réthoré J, Hild F (2009) Digital image correlation and fracture: an advanced technique for estimating stress intensity factors of 2D and 3D cracks. J Phys D Appl Phys 42:214004

Rupil J, Roux S, Hild F, Vincent L (2011) Fatigue microcrack detection with digital image correlation. J Strain Anal Eng Des 46:492-509

Ryall TG, Fraser CS (2002) Determination of structural modes of vibration using digital photogrammetry. J Aircr 39:114-119

Sabnavis G, Kirk R, Kasarda M (2004) Cracked shaft detection and diagnostics: a literature review. Shock Vib Dig 36:287-296

Sakurai S (1997) Lessons learned from field measurements in tunnelling. Tunn Undergr Space Technol 12:453-460. https://doi.org/10.1016/S0886-7798(98)00004-2

Salawu O (1997) Detection of structural damage through changes in frequency: a review. Eng Struct 19:718-723

Salganik RL (1973) Mechanics of bodies with many cracks. Mech Solids 8:135-143

Samanta B (2004) Gear fault detection using artificial neural networks and support vector machines with genetic algorithms. Mech Syst Signal Process 18:625-644. https://doi. org/10.1016/s0888-3270(03)00020-7

Samuel MP, Jha MK (2003) Estimation of aquifer parameters from pumping test data by genetic algorithm optimization technique. J Irrig Drain Eng 129:348-359. https://doi.org/ 10.1061/(ASCE)0733-9437(2003)129:5(348)

Sawmliana C, Roy PP, Singh RK, Singh TN (2007) Blast induced air overpressure and its prediction using artificial neural network. Min Technol 116:41-48

Sazonov E, Li H, Curry D, Pillay P (2009) Self-powered sensors for monitoring of highway bridges. IEEE Sens J 9:1422-1429. https://doi.org/10.1109/JSEN.2009. 2019333

Schlichting J, Brauser S, Pepke LA, Maierhofer C, Rethmeier M, Kreutzbruck M (2012) Thermographic testing of spot welds. NDT E Int 48:23-29. https://doi.org/10.1016/j. ndteint.2012.02.003

Schneider B (1983) Drilling logs for earth dam leakage location. Bull Int Assoc Eng Geol 26-27:59-63

Schreier HW, Sutton MA (2002) Systematic errors in digital image correlation due to undermatched subset shape functions. Exp Mech 42:303-310. https://doi.org/10.1007/ bf02410987

Shahin M, Elchalakani M (2008) Neural networks for modelling ultimate pure bending of steel circular tubes. J Constr Steel Res 64:624-633. https://doi.org/10.1016/j.jcsr.2007.12. 001

Sham FC, Chen N, Long L (2008) Surface crack detection by flash thermography on concrete surface. Insight Non Destr Test Cond Monit 50:240-243. https://doi.org/10.1784/insi. 2008.50.5.240

Shi GH (1992) Manifold method of material analysis. Defense Technical Information Center, Fort Belvoir

Shigeto Y, Sakai M (2011) Parallel computing of discrete element method on multi-core processors. Particuology 9:398-405

Shishavan RA, Hubbell C, Perez HD, Hedengren JD, Pixton DS, Pink AP (2016) Multivariate control for managed- 
pressure-drilling systems by use of high-speed telemetry. SPE J 21:459-470

Shufrin I, Pasternak E, Dyskin AV (2016) Deformation analysis of reinforced-core auxetic assemblies by close-range photogrammetry. Phys Status Solidi B 253:1342-1358. https:// doi.org/10.1002/pssb.201552723

Simkins DC, Li S (2006) Meshfree simulations of thermo-mechanical ductile fracture. Comput Mech 38:235-249. https://doi.org/10.1007/s00466-005-0744-8

Singh RN, Denby B, Egretli I (1987) Development of new rippability index for coal measures excavations. In: 28th US symposium on rock mechanics, Tuscon, US, pp 935-943

Singh T, Sinha S, Singh V (2007) Prediction of thermal conductivity of rock through physico-mechanical properties. Build Environ 42:146-155

Singh R, Vishal V, Singh T, Ranjith P (2013) A comparative study of generalized regression neural network approach and adaptive neuro-fuzzy inference systems for prediction of unconfined compressive strength of rock. Neural Comput Appl 23:499-506

Sohn H, Kim SB (2010) Development of dual PZT transducers for reference-free crack detection in thin plate structures. IEEE Trans Ultrason Ferroelectr Freq Control 57:229-240. https://doi.org/10.1109/TUFFC.2010.1401

Sonmez H, Gokceoglu C, Ulusay R (2003) An application of fuzzy sets to the geological strength index (GSI) system used in rock engineering. Eng Appl Artif Intell 16:251-269

Stepinski T, Uhl T, Staszewski W (2013) Advanced structural damage detection: from theory to engineering applications. Wiley, London

Strbac V, Vander Sloten J, Famaey N (2015) Analyzing the potential of GPGPUs for real-time explicit finite element analysis of soft tissue deformation using CUDA. Finite Elem Anal Des 105:79-89. https://doi.org/10.1016/j.finel. 2015.07.005

Tahmeen M, Hareland G, Aadnoy BS (2014) Real-time software to estimate friction coefficient and downhole weight on bit during drilling of horizontal wells. In: Proceedings of the international conference on offshore mechanics and arctic engineering-OMAE. https://doi.org/10.1115/omae201424620

Tao H, Jin B, Zhong W, Wang X, Ren B, Zhang Y, Xiao R (2010) Discrete element method modeling of non-spherical granular flow in rectangular hopper. Chem Eng Process 49:151-158

Thatoi DN, Das HC, Parhi DR (2012) Review of techniques for fault diagnosis in damaged structure and engineering system. Adv Mech Eng. https://doi.org/10.1155/2012/327569

Theodorakeas P, Cheilakou E, Ftikou E, Koui M (2015) Passive and active infrared thermography: an overview of applications for the inspection of mosaic structures. J Phys: Conf Ser 655:012061

Timoshenko SP, Goodier JN (1970) Theory of elasticity, 3rd edn. McGraw-Hill, New York

Tordrup KW, Poulsen SE, Bjørn H (2017) An improved method for upscaling borehole thermal energy storage using inverse finite element modelling. Renew Energy 105:13-21. https://doi.org/10.1016/j.renene.2016.12.011

Uhl T, Hanc A, Tworkowski K, Sekiewicz Ł (2007) Wireless sensor network based bridge monitoring system. Key Eng
Mater 347:499-504. https://doi.org/10.4028/www. scientific.net/KEM.347.499

Valença J, Dias-da-Costa D, Júlio ENBS (2012) Characterisation of concrete cracking during laboratorial tests using image processing. Constr Build Mater 28:607-615. https:// doi.org/10.1016/j.conbuildmat.2011.08.082

Varadan VK, Varadan VV (2000) Microsensors, microelectromechanical systems (MEMS), and electronics for smart structures and systems. Smart Mater Struct 9:953-972

Vavakin AS, Salganik RL (1975) Effective characteristics of non-homogeneous media with isolated nonhomogeneities. Mech Solids 10:58-66

Vavakin AS, Salganik RL (1978) Effective elastic characteristics of bodies with isolated cracks voids and rigid nonhomogeneities. Mech Solids 13:87-97

Veeningen DM (2011) Along-string pressure evaluation enabled by broadband networked drillstring provide safety, efficiency gains. Paper presented at the offshore technology conference, Rio de Janeiro, Brazil, 4-6 Oct 2011

Vendroux G, Knauss WG (1998) Submicron deformation field measurements: part 2. Improved digital image correlation. Exp Mech 38:86-92. https://doi.org/10.1007/bf02321649

Verma A, Kusiak A (2012) Fault monitoring of wind turbine generator brushes: a data-mining approach. J Sol Energy Eng Trans ASME. https://doi.org/10.1115/1.4005624

Walsh JB (1975) An analysis of local changes gravity due to deformation. Pure appl Geophys 113:97-106

Wang H, Kang Y (2002) Improved digital speckle correlation method and its application in fracture analysis of metallic foil. Opt Eng 41:2793-2798

Wauer J (1990) Dynamics of cracked rotors: literature survey. Appl Mech Rev 43:13-17

Weaver JM (1975) Geological factors significant in the assessment of rippability. Civ Eng S Afr 17:131-136

Widodo A, Yang BS (2007) Support vector machine in machine condition monitoring and fault diagnosis. Mech Syst Signal Process 21:2560-2574. https://doi.org/10.1016/j.ymssp. 2006.12.007

Wiles TD, Kaiser PK (1994a) In situ stress determination using the under-excavation technique-I. Theory. Int J Rock Mech Min Sci 31:439-446. https://doi.org/10.1016/01489062(94)90147-3

Wiles TD, Kaiser PK (1994b) In situ stress determination using the under-excavation technique-II. Applications. Int J Rock Mech Min Sci 31:447-456. https://doi.org/10.1016/ 0148-9062(94)90148-1

Willberg D, Desroches P, Babour K, Gzara K, Besson C (2006) Mapping fracture dimensions. USA Patent

Wittek A, Grosland N, Joldes G, Magnotta V, Miller K (2016) From finite element meshes to clouds of points: a review of methods for generation of computational biomechanics models for patient-specific applications. Ann Biomed Eng 44:3-15. https://doi.org/10.1007/s10439-015-1469-2

Worden K, Dulieu-Barton JM (2004) An overview of intelligent fault detection in systems and structures. Int J Struct Health Monit 3:85-98

Xiongyao X, Yujian L, Hongwei H, Jun D, Fengshou Z, Lanbo L (2007) Evaluation of grout behind the lining of shield tunnels using ground-penetrating radar in the Shanghai Metro Line, China. J Geophys Eng 4:253 
Yan J, Heng-Hu Y, Hong Y, Feng Z, Zhen L, Ping W, Yan Y (2015) Nondestructive detection of valves using acoustic emission technique. Adv Mater Sci Eng. https://doi.org/10. $1155 / 2015 / 749371$

Ye J, Fu G, Poudel UP (2011) Edge-based close-range digital photogrammetry for structural deformation measurement. J Eng Mech 137:475-483. https://doi.org/10.1061/ (asce)em.1943-7889.0000251

Yelf R, Yelf D, Al-Nuaimy W (2008) Classification system for ground penetrating radar parameters. Electromagn Phenom $7: 150-157$

Yilmaz I, Kaynar O (2011) Multiple regression, ANN (RBF, MLP) and ANFIS models for prediction of swell potential of clayey soils. Expert Syst Appl 38:5958-5966

Yilmaz I, Yuksek G (2009) Prediction of the strength and elasticity modulus of gypsum using multiple regression, ANN, and ANFIS models. Int $J$ Rock Mech Min Sci 46:803-810

Yoshida H, Kumar S, Morita Y (2001) Online fault detection and diagnosis in VAV air handling unit by RARX modeling. Energy Build 33:391-401. https://doi.org/10.1016/ S0378-7788(00)00121-3

Yue ZQ, Chen S, Tham LG (2003) Finite element modeling of geomaterials using digital image processing. Comput Geotech 30:375-397. https://doi.org/10.1016/s0266$352 x(03) 00015-6$

Zadeh LA (1965) Fuzzy sets. Inf Control 8:338-353

Zaitsev VY, Radostin AV, Pasternak E, Dyskin A (2017a) Extracting real-crack properties from non-linear elastic behaviour of rocks: abundance of cracks with dominating normal compliance and rocks with negative Poisson ratios. Nonlinear Processes Geophys 24:543-551. https://doi.org/ 10.5194/npg-24-543-2017

Zaitsev VY, Radostin AV, Pasternak E, Dyskin A (2017b) Extracting shear and normal compliances of crack-like defects from pressure dependences of elastic-wave velocities. Int J Rock Mech Min Sci 97:122-133. https://doi.org/ 10.1016/j.ijrmms.2017.04.009

Zaki A, Chai HK, Aggelis DG, Alver N (2015) Non-destructive evaluation for corrosion monitoring in concrete: a review and capability of acoustic emission technique. Sensors 15:19069-19101. https://doi.org/10.3390/s150819069

Zaremba N, Lehane B (2007) The performance of steel struts in a braced excavation in Perth. Aust Geomech 42:121-132

Zhang X, Lu MW, Wegner JL (2000) A 2-D meshless model for jointed rock structures. Int $\mathrm{J}$ Numer Methods Eng 47:1649-1661. https://doi.org/10.1002/(SICI)10970207(20000410)47:10<1649::AID-NME843>3.0.CO;2-S

Zhang Z-F, Kang Y-L, Wang H-W, Qin Q-H, Qiu Y, Li X-Q (2006) A novel coarse-fine search scheme for digital image correlation method. Measurement 39:710-718

Zhang P, Du Y, Habetler TG, Lu B (2011) A survey of condition monitoring and protection methods for medium-voltage induction motors. IEEE Trans Ind Appl 47:34-46. https:// doi.org/10.1109/tia.2010.2090839

Zhang D, Zhu W, Li S, Zhang B, Wang W (2012a) A modified maximum tangential tensile stress criterion for three-dimensional crack propagation. J Rock Mech Geotech Eng 4:62-72. https://doi.org/10.3724/SP.J.1235.2012.00062
Zhang JY, Joldes GR, Wittek A, Horton A, Warfield SK, Miller K (2012b) Neuroimage as a biomechanical model: toward new computational biomechanics of the brain. In: Nielsen PMF, Wittek A, Miller K (eds) Computational biomechanics for medicine. Deformation and flow. Springer, New York, pp 19-28. https://doi.org/10.1007/978-1-46143172-5_4

Zhang YJ, Joldes GR, Wittek A, Miller K (2013) Patientspecific computational biomechanics of the brain without segmentation and meshing. Int J Numer Methods Biomed Eng 29:16. https://doi.org/10.1002/cnm.2507

Zhang GY, Wittek A, Joldes GR, Jin X, Miller K (2014) A threedimensional nonlinear meshfree algorithm for simulating mechanical responses of soft tissue. Eng Anal Bound Elem 42:60-66. https://doi.org/10.1016/j.enganabound.2013.08. 014

Zhang Y, O’Neill Z, Dong B, Augenbroe G (2015) Comparisons of inverse modeling approaches for predicting building energy performance. Build Environ 86:177-190. https:// doi.org/10.1016/j.buildenv.2014.12.023

Zhao F, Guibas LJ (2004) Wireless sensor networks: an information processing approach. Morgan Kaufmann, Los Altos

Zhao GF, Fang JN, Zhao J (2011) A 3D distinct lattice spring model for elasticity and dynamic failure. Int J Numer Anal Methods Geomech 35:859-885. https://doi.org/10.1002/ nag.930

Zhou C-B, Liu W, Chen Y-F, Hu R, Wei K (2015a) Inverse modeling of leakage through a rockfill dam foundation during its construction stage using transient flow model, neural network and genetic algorithm. Eng Geol 187:183-195. https://doi.org/10.1016/j.enggeo.2015.01. 008

Zhou XP, Zhao Y, Qian QH (2015b) A novel meshless numerical method for modeling progressive failure processes of slopes. Eng Geol 192:139-153. https://doi.org/ 10.1016/j.enggeo.2015.04.005

Zhu X, Tang L, Yang Q (2014) A literature review of approaches for stick-slip vibration suppression in oilwell drillstring. Adv Mech Eng. https://doi.org/10.1155/2014/ 967952

Zienkiewicz OC (1965) Cheung finite elements in the solution of field problems. Engineer 220:507-510

Zienkiewicz O, Cheung Y (1966) Application of the finite element method to problems of rock mechanics. In: 1st ISRM Congress. International Society for Rock Mechanics

Zienkiewicz O, Cheung Y, Stagg KG (1966) Stresses in anisotropic media with particular reference to problems of rock mechanics. J Strain Anal Eng Des 1:172-182

Zienkiewicz O, Valliappan S, King I (1968) Stress analysis of rock as a 'no tension' material. Geotechnique 18:56-66

Zienkiewicz O, Valliappan S, Ergatoudis J (1970) Finite element analysis in rock mechanics: a general review. CIRIA Technical Note, 4-15

Zienkiewicz OC, Taylor RL, Zienkiewicz OC, Taylor RL (1977) The finite element method. McGraw-Hill, London

Zienkiewicz OC, Chan A, Pastor M, Schrefler B, Shiomi T (1999) Computational geomechanics. Wiley, Chichester 